\title{
Design, Fabrication and Modification of Metal Oxide Semiconductor for Improving Conversion Efficiency of Excitonic Solar Cells
}

\author{
Jianjun Tian ${ }^{1,2}$ and Guozhong $\mathrm{Cao}^{1,3 *}$ \\ ${ }^{1}$ Beijing Institute of Nanoenergy and Nanosystems, Chinese Academy of Sciences, 100083, P.R. China. \\ ${ }^{2}$ Institute of Advanced Material and Technology, University of Science and Technology Beijing, 100083, P.R. \\ China. Email: tianjianjun@mater.ustb.edu.cn \\ ${ }^{3}$ Department of Materials and Engineering, University of Washington, Seattle, WA 98195-2120, USA. Email: \\ gzcao@u.washington.edu
}

\section{Contents}

1. Introduction 3

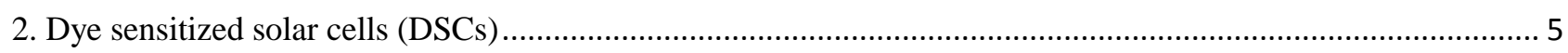

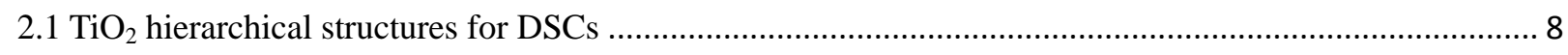

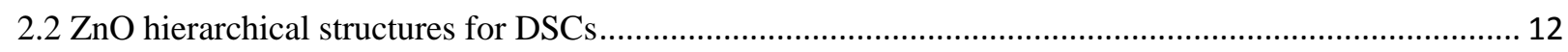

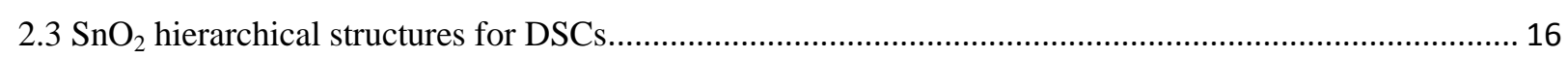

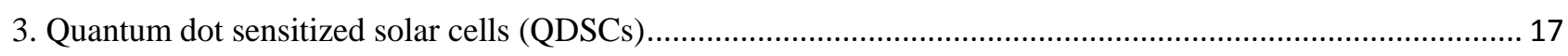

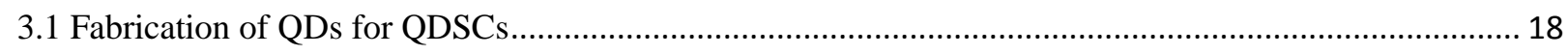

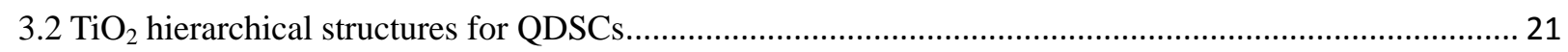

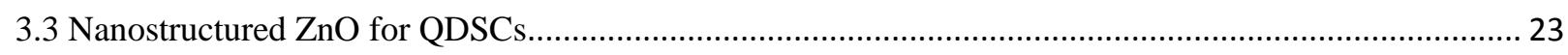

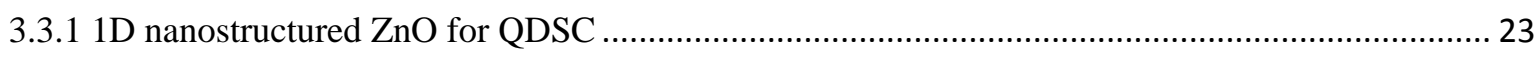

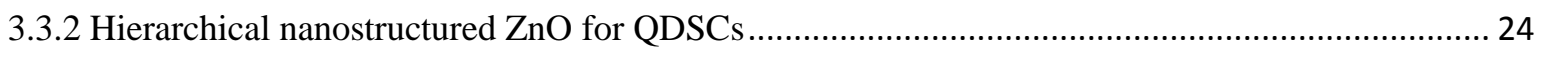

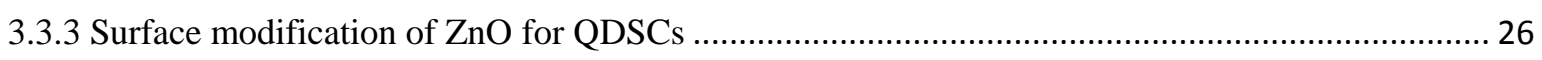

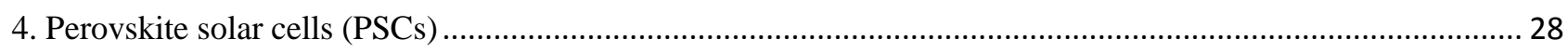

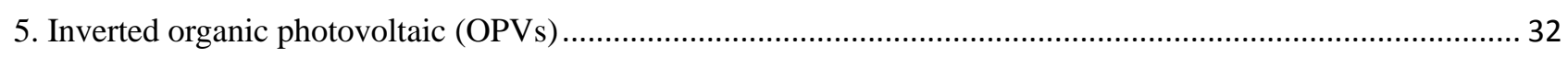

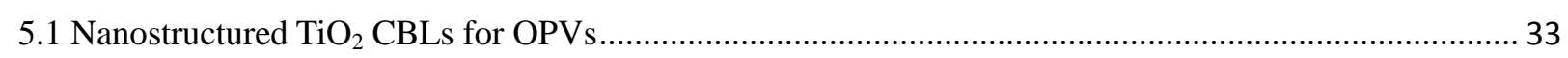

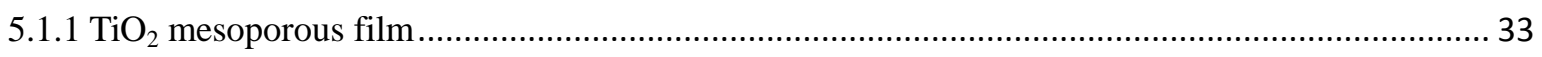

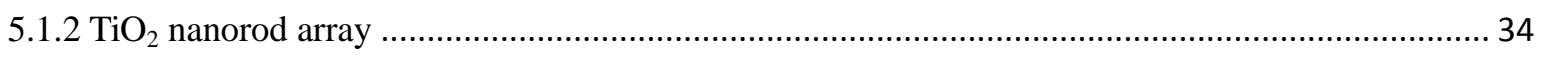

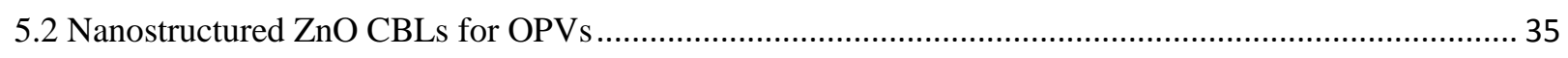

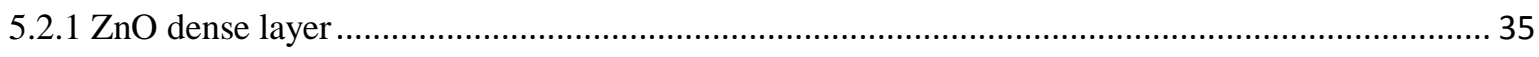

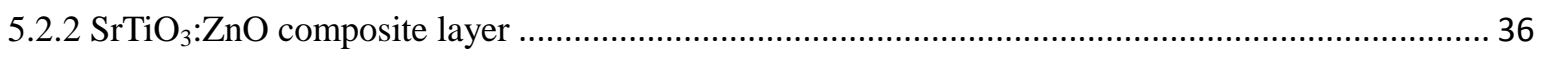

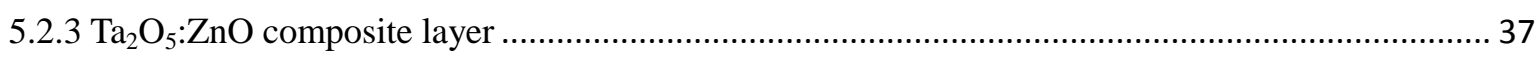

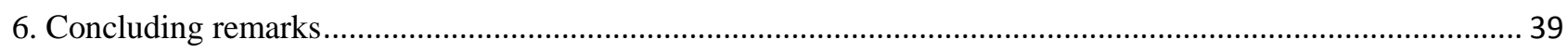

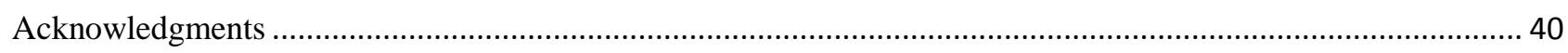

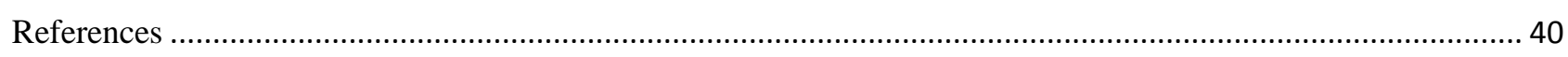

\begin{abstract}
:
Excitonic solar cells (ESCs) including dye-sensitized solar cells (DSCs), quantum dot-sensitized solar cells (QDSCs), perovskites solar cells (PSCs) and inverted organic photovoltaics (OPVs), are built upon metal oxide semiconductors (MOSs), which have attracted considerable attention recently and showed a promising
\end{abstract}


development for the next generation solar cells. The development of nanotechnology has created various MOS nanostructures to open up new perspectives for their exploitation, significantly improving the performances of ESCs. One of the outstanding advantages is that the nanostructured mesoporous MOSs offer large specific surface area for loading a large amount of active materials (dyes, quantum dots or perovskites) so as to capture a sufficient fraction of photons as well as to facilitate efficient charge transfer. This review focuses on the recent work on the design, fabrication and surface modification of nanostructured MOSs to improve the performance of ESCs. The key issues for the improvement of efficiency, such as enhancing light harvesting and reducing surface charge recombination, are discussed in this paper.

Key words: Metal oxide semiconductors, dye sensitized solar cell, quantum dot sensitized solar cells, perovskites solar cells, inverted organic photovoltaics.

\section{Abbreviations:}

1D, one-dimensional; 2D, two-dimensional; 3D, three-dimensional; ABL, anode buffer layer; AFM, atomic force microscopy; ALD, atomic layer deposition; CBD, chemical bath deposition; CBL, cathode buffer layer; DSC, dye-sensitized solar cell; EDS, X-ray energy dispersive; spectroscopy; EDX, energy dispersive X-ray; EIS, electrochemical impedance spectroscopy; ESC, excitonic solar cells; FESEM, field emission scanning electron microscopy; FF, fill factor; FTIR, Fourier transform infrared spectroscopy; FTO, F-doped tin oxide; HRTEM, high resolution transmission microscope; HTM, hole transport material; IPCE, incident photon-to-current conversion efficiency; ITO, indium tin oxide; $\mathrm{J}_{\mathrm{sc}}$, current density; MEG, multiple exciton generation; LUMO, lowest unoccupied molecular orbital; MOS, metal oxide semiconductor; OPV, organic photovoltaic; P3HT, poly(3-hexylthiophène); pcAFM, photoconductive atomic force microscopy; PCBM, [6,6]-phenyl-C61-butyric acid methyl ester; PCE, power conversion efficiency; PEDOT, poly(3,4-ethylenedioxythiophene); PL, photoluminescence spectra; PSC, perovskites solar cell; QD, quantum dot; QDSC, quantum dot-sensitized solar cell; SAED, selected area electron diffraction; SEM, scanning electron microscope; SKPM, scanning Kelvin probe force microscopy; SILAR, successive ionic layer absorption and reaction; $\mathrm{SnO}_{2}$, tin dioxide; TEM, transmission electron microscopy; $\mathrm{TiO}_{2}$, titanium dioxide; $\mathrm{UV}$-vis, ultraviolet and visible light; $\mathrm{V}_{\text {oc }}$, open voltage; XPS, X-ray photoelectron spectroscopy; XRD, X-ray diffraction; ZnO, zinc oxide. 


\section{Introduction}

Transition metal oxides, particularly those wide bandgap metal oxide semiconductors (MOSs), such as titanium dioxide $\left(\mathrm{TiO}_{2}\right)$, zinc oxide $(\mathrm{ZnO})$ and tin dioxide $\left(\mathrm{SnO}_{2}\right)$ have found wide applications in sustainable clean energy, including solar cells, solar fuel, photo catalysis and energy storage devices due to their natural abundance, chemical inertness, and excellent photoelectric and electrochemical properties[1-7]. In the past decades, the development of nanotechnology has created various MOS nanostructures to open up new perspectives for their exploitation, significantly improving the performances of end-user devices including lithium, sodium and magnesium ion batteries and supercapacitors[8-10], especially in the next generation solar cells[11-13]. As the traditional photovoltaics, the p-n junction crystalline silicon (c-Si) solar cells suffer from high cost of manufacturing and installation and long energy payback time $[14,15]$, There is an imperative demand for the development of low cost and high performance solar cells to allow sustainable energy sources to replace fossil fuels $[14,16]$. As a cost effective alternative to silicon based photovoltaics, excitonic solar cells (ESCs) including dye-sensitized solar cells (DSCs), quantum dot-sensitized solar cells (QDSCs), perovskites solar cells (PSCs) and inverted polymer solar cells or inverted organic photovoltaics (OPVs), based upon nanostructured MOSs have attracted considerable attention recently and showed a promising development for the next generation solar cells [17-23]. MOS plays an very important role in ESCs either as electron transporting layer while blocking hole transport (known as cathode buffer layer) or as hole transporting layer while blocking the electron transport (anode buffer layer)[13].

As early as 1991, MOS $\mathrm{TiO}_{2}$ with porous nanostructure was successfully used in DSCs to get high power conversion efficiency (PCE) of greater than 7\%, which was a significant breakthrough for the next generation solar cells with low cost[22]. DSC is a category of photovoltaic device based on a photo-electrochemical system in which a porous MOS film with dye molecules adsorbed on the surface serving as the working electrode for light harvesting and the generation of photoexcited electrons [24]. Many efforts have been focused on improving light absorption of sensitizers [25-28]. In 2014, a recorded PCE of 13\% of DSC has been obtained by using a molecularly engineered porphyrin dye coded SM315 and the cobalt (II/III) redox electrolyte[29]. In comparison with c-Si solar cells, PCE of DSCs still is much low. One of the effective approaches is to developing new sensitizers for absorbing photons in the full sunlight spectra. Narrow-band-gap semiconductor quantum dots (QDs) with wide light absorption region, such as $\operatorname{CdS}[30,31], \mathrm{CdSe}[23,32], \mathrm{PbS}[33]$ and $\operatorname{InAs}[34]$ have been investigated as photo-sensitizers instead of organic dyes to form QDSCs that have attracted a lot of attention 
particularly due to: (1) adjustable band gap through design and control the size of QD, (2) good chemical stability (3) much efficient light absorption (a high extinction coefficient) and (4) multiple exciton generation (MEG) promising a power conversion efficiency theoretically up to $40 \%$ in a single junction solar cell [35-37]. Practically efficiencies in the range of 6\% for $\mathrm{CdSe}[38,39]$ and $8 \%$ for $\mathrm{CdSeTe}[40-42]$ QDSCs have already been achieved; the PCE of QDSCs remains lower than that of DSCs, due likely to large surface charge recombination, attributable to the surface imperfection of QDs and the less ideal contact between QDs and MOS scaffold[43]. In 2009, Miyasaka group reported the solar cells with DSC structure using organic-inorganic hybrid perovskite $\mathrm{CH}_{3} \mathrm{NH}_{3} \mathrm{PbBr}_{3}$ and $\mathrm{CH}_{3} \mathrm{NH}_{3} \mathrm{PbI}_{3}$ as visible-light sensitizers instead of organic dyes[44]. This attempt led to PCE of 3.8\%. Although, the PCE was low, the attempt provided a new approach for the next generation solar cells [45]. In 2011, Park's group reported a 6.5\% efficient $\mathrm{CH}_{3} \mathrm{NH}_{3} \mathrm{PbI}_{3}$ PSC [46], though this work did not attract much attention due to the liquid electrolyte used in the devices. In 2012, an all solid ESC using perovskite with a PCE greater than 10\% was obtained by Snaith's group, which had attracted worldwide attention[47]. In 2015, PSCs based on the $\mathrm{MOS} \mathrm{TiO}_{2}$ assembled with $\mathrm{CH}_{3} \mathrm{NH}_{3} \mathrm{PbX}$ achieved $\mathrm{PCE}$ of greater than 20\%[48]. In recent years, OPVs have attracted extensive investigation as one of ESCs, mainly due to their inherent advantages of being low-cost, and compatible with flexible substrate and solution-based roll-to-roll processing technique [17-21, 49]. Compared with the organic photovoltaics with a traditional structure, which typically have a configuration ITO/PEDOT/P3HT:PCBM/MOS/Al, inverted OPVs with the configuration ITO/MOS/PCBM:P3HT/PEDOT/Ag avoid the contact of ITO with PEDOT (which degrades the conductivity of ITO glass) and allow the use of high work function metal (e.g., Ag) as top electrode, and can therefore significantly enhance the stability of polymer solar cells [13].

Among various MOSs, $\mathrm{TiO}_{2}, \mathrm{ZnO}$ and $\mathrm{SnO}_{2}$ have been studied widely in ESCs, due to their matching band structure, excellent physical properties and high electronic mobility[50-55]. Table 1 shows structural and electronic characteristics of $\mathrm{TiO}_{2}, \mathrm{ZnO}$ and $\mathrm{SnO}_{2}$ [56]. It can be seen that $\mathrm{TiO}_{2}, \mathrm{ZnO}$ and $\mathrm{SnO}_{2}$ have similar band structure and physical properties. In the past decades, more and more efforts have been focused on the application of $\mathrm{TiO}_{2}, \mathrm{ZnO}$ and $\mathrm{SnO}_{2}$ in ESCs. For example, Figure 1 displays the evolution of the number of publications for 'dye sensitized solar cell'. In addition to research works, many excellent review and perspective articles have covered the fundamentals and technical approaches for the design, fabrication, and characterization of MOSs for ESCs [11, 51, 54, 57-62]. In this review, we would focus mainly on the recent work on the MOS structure and their interface for improving the efficiency of ESCs, such as enhancing light harvesting and reducing surface charge recombination. 
Table 1. Structural and electronic characteristics of $\mathrm{TiO}_{2}, \mathrm{ZnO}$ and $\mathrm{SnO}_{2}$. [56]

\begin{tabular}{cccccccc}
\hline $\mathrm{MOSs}$ & $\begin{array}{c}\text { Crystal } \\
\text { structure }\end{array}$ & $\begin{array}{c}\text { Band } \\
\text { gap / } \\
\mathrm{eV}\end{array}$ & $\begin{array}{c}\text { Conduction } \\
\text { Band Minimum } \\
/ \mathrm{eV}\end{array}$ & $\begin{array}{c}\text { Electron } \\
\text { Effective } \\
\text { Mass }\end{array}$ & $\begin{array}{c}\text { Static } \\
\text { Dielectric } \\
\text { Constant }\end{array}$ & $\begin{array}{c}\text { Electron } \\
\text { Mobility } \\
/ \mathrm{cm}^{2} \mathrm{~V}^{-1} \mathrm{~s}^{-1}\end{array}$ & $\begin{array}{c}\text { Electron } \\
\text { Diffusion } \\
\text { Coefficient } \\
\text { (nanoporous } \\
\text { film) } / \mathrm{cm}^{2} \mathrm{~s}^{-1}\end{array}$ \\
\hline $\mathrm{TiO}_{2}$ & $\begin{array}{c}\text { Rutile, } \\
\text { Anatase }\end{array}$ & $3.0-3.2$ & -4.41 & 9 & 86,170 & $0.1-4$ & $4.3 \times 10^{-4}$ \\
$\mathrm{ZnO}$ & Wurtzite & $3.2-3.4$ & -4.36 & 0.26 & $9.26,8.2$ & $130-200$ & $1.1 \times 10^{-4}$ \\
$\mathrm{SnO}_{2}$ & Rutile & $3.6-3.8$ & -4.88 & 0.275 & 14,9 & $200-250$ & $7.3 \times 10^{-5}$ \\
\hline
\end{tabular}

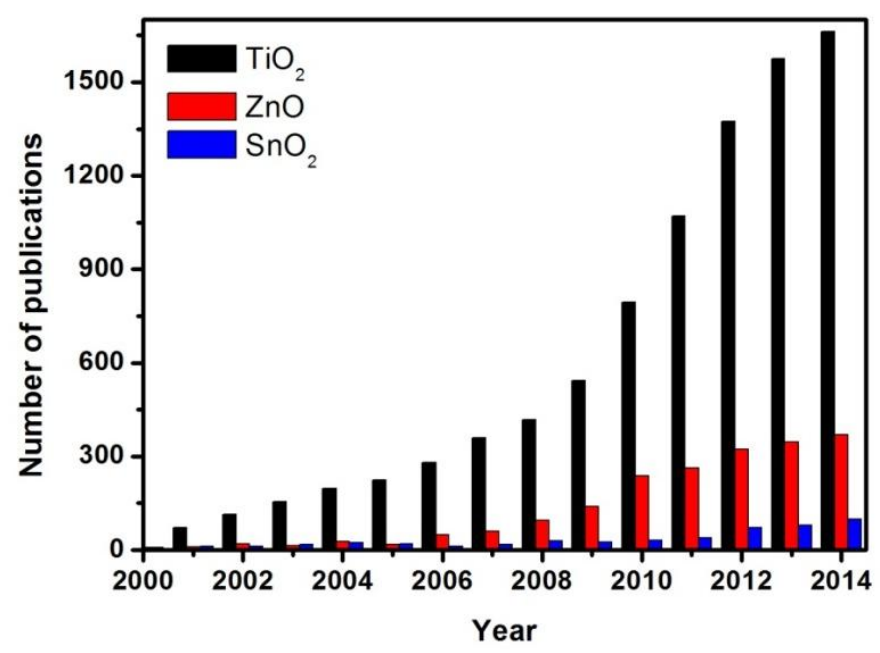

Figure 1. Evolution of the number of publications for 'dye sensitized solar cell' with ' $\mathrm{TiO}_{2}$ ', ' $\mathrm{ZnO}$ ' and ' $\mathrm{SnO}_{2}$ ', respectively. Source: ISI Web of Science, Thomson Reuters.

\section{Dye sensitized solar cells (DSCs)}

DSCs are in essence a photoelectron-chemical system as shown in Figure 2 [63]. Nanostructured MOS films are the framework of DSC photoanodes, which serve dual functions as the support for sensitizer loading and transporter of photo-excited electrons from sensitizer to external circuit[58]. Usually, a layer of MOS with the thickness 10 to $20 \mu \mathrm{m}$ is prepared on a glass substrate coated with a transparent conductive film. The other electrode, the so-called counter electrode, is a glass or silicon substrate coated with a platinum film. As a conductive medium, the liquid electrolyte with $\mathrm{I}^{-} / \mathrm{I}_{3}{ }^{-}$redox couples is filled in the gaps of MOS and the space between the photoanode and counter electrode. The work process of DSC is [63] : the light irradiating from the photoanode side is captured by the dye molecules that are adsorbed on the oxide, leading to the generation of 
photoexcited electrons in the dye molecules; the photogenerated electrons then transfer into the oxide, diffuse in the oxide, and are finally collected by the transparent conductive film on the glass substrate, which is connected to external circuit; the photooxidized dye molecules are reduced by electrons provided by $\mathrm{I}^{-} / \mathrm{I}_{3}{ }^{-}$redox couples in the electrolyte. Those photogenerated electrons at the photoanode travel through the external circuit, reach the platinum-coated counter electrode and, finally, gain access to the electrolyte, reducing $\mathrm{I}^{-} / \mathrm{I}_{3}{ }^{-}$redox couples and enabling the electrolyte to be regenerated. In DSCs, the structure of photoanodes has important effect on the light harvesting and photoexcited electrons transport. Not only does the nanostructured MOS offer large surface area to adsorb a large amount of dyes for light harvesting, but also collects the electrons from dyes and transfers them to electrodes. MOS nanoparticles film is first used in DSCs due to its large surface area for loading dyes. But it is not an ideal structure in regard to the electron transport $[12,64]$. The first non-ideality results from the lack of a macroscopic electrostatic potential gradient in the film due to the fact that the film is permeated with a concentrated electrolyte [12]. The mesoporous films are very much different compared to their compact analogues because (i) the inherent conductivity of the film is very low, (ii) the small size of the individual colloidal particles does not support a built-in electrical field, and (iii) the oxide particles and the electrolyte-containing pores form interpenetrating networks whose phase boundaries produce a junction of huge contact area [65]. Therefore, the electron transport in the nanoparticle film is dominated by a process of diffusion instead of drift. The drift is a common way in p-n junction solar cells for carrier separation in the presence of an electric field. The second non-ideality comes from the fact that the electron transport in a nanoparticle film undergoes a trapping and detrapping process as shown in Figure 3. Numerous grain boundaries, interface defects and connections existing in the nanoparticle film also increase the surface charge recombination, and retard effective charge injection and charge transport, which result in a loss of PCE. So many efforts have been made on the synthesis of a variety of nanostructured MOS photoanodes in the forms of wires, tubes, spheres, rods, sheets, belts, flowers and trees for the efficient DSC devices[66-73]. 


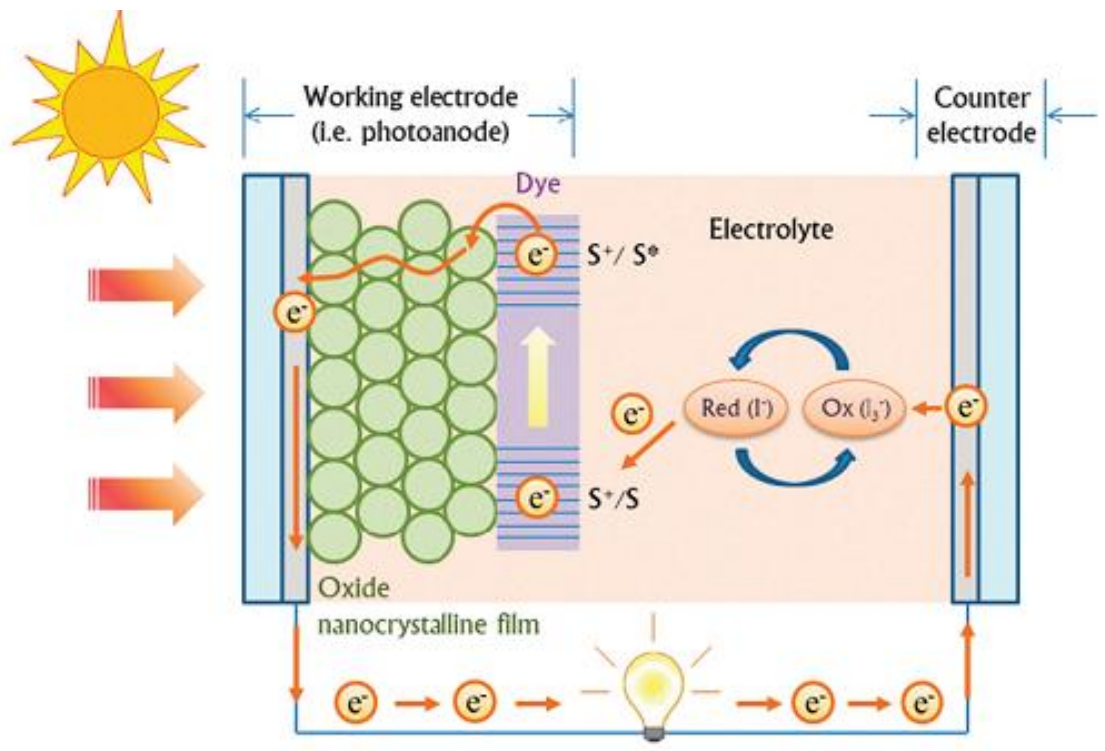

Figure 2. Structure and operating mechanism of a DSC. Reprinted from reference [63].

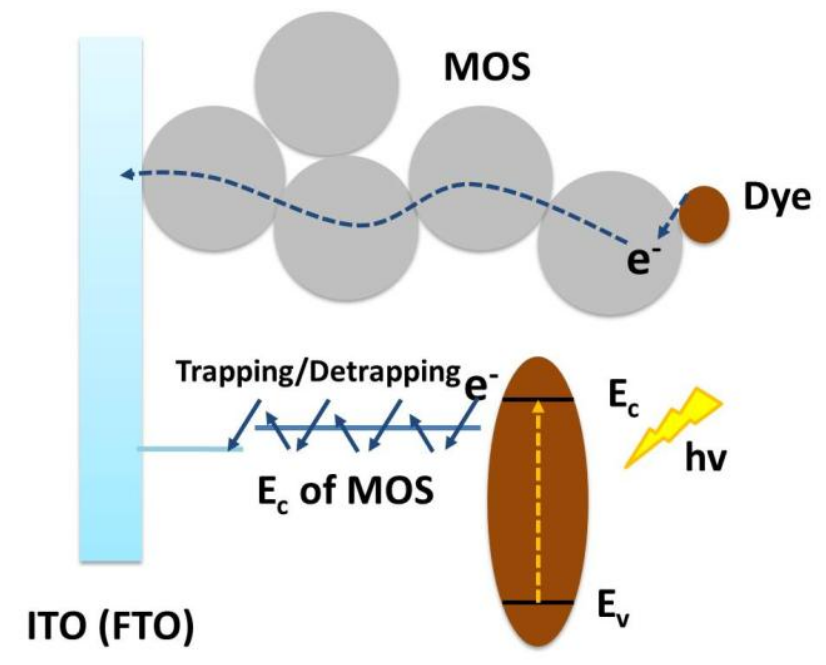

Figure 3. Schematic illustrations of electron transport in a nanoparticle film suffering a trapping/detrapping process

To increase the electron mobility and reduce grain boundaries and interfaces, one-dimensional (1D) nanostructures, such as nanotube arrays and single-crystalline nanowire arrays, have been studied as photoanodes for DSCs[66]. However, DSCs based on 1D structures have not reached high conversion efficiency as expected due to the much small surface area for dye adsorption[74]. The 3D hierarchical nanostructures can offer larger surface areas for dye adsorption while simultaneously enhancing light scattering for efficient photon harvesting, and thereby, improving PCE[70, 74-76]. The aggregate structure consisting of primary nanocrystallites can provide both large specific surface area and light scattering effect so as to enhance the performance of DSCs [8, $12,24,76-79]$. In addition, the diffusion of electrolyte in the aggregate structure is faster than that in nanoparticle film, which boosts the charge transport. Our previous works [12, 24, 77, 79-82] showed that the photoanodes with 
the hierarchical aggregates structure are promising for the highly efficiency DSCs. Our recent works have been continuing to improve the fabrication and design of the hierarchical structure of MOSs for increasing the PCE of DSCs.

\section{1 $\mathrm{TiO}_{2}$ hierarchical structures for DSCs}

In the last few decades, many methods have been used to synthesize $\mathrm{TiO}_{2}$ nanostructrues, such as sol-gel processing [83], hydrothermal[84], solvothermal[85] and template growth [86] approaches. The hydrothermal and solvonthermal methods have been frequently used for the reason that they are readily capable of obtaining the desired size and structure of $\mathrm{TiO}_{2}$ nanocrystals by controlling the temperature and duration of the reaction, and the type and concentration of the reactants, as well as the solvent and additives used. However, defects in the resultant nnaocrystals like complex and time-consuming process have been pointed out in the hydrothermal and solvothermal methods. The high cost and low productivity of the hydrothermal and solvothermal methods are also considered as a big hindrance for their applications in DSCs. There is a growing need to develop a fast and high productivity synthesis method to obtain $\mathrm{TiO}_{2}$ nanocrystals for the application in DSCs. Compared with hydrothermal and solvothermal methods, the microwave assisted synthesis offers rapid processing speed, homogeneous heating and simple control of processing conditions, and thus has attracted much attention in the last few years [87]. Recently, microwave assisted synthesis was employed to fabricate hierarchically structured $\mathrm{TiO}_{2}$ nanocrystallite aggregates, which are shown in Figure 4[88]. Hierarchically structured $\mathrm{TiO}_{2}$ nanocrystallite aggregates with a size of $\sim 500 \mathrm{~nm}$ in diameter consisted of $\sim 10 \mathrm{~nm}$ nanocrystallites were synthesized by microwave assisted method at $150^{\circ} \mathrm{C}$ in a short time ( 10 minutes) using ethanol and $\mathrm{TiCl}_{4}$ as the solvent and titanium precursor, respectively. The rapid heating rate and superheating / "hot spots" of the reaction system under microwave irradiation resulted in huge supersaturation leading to a high density of nuclei instantly so as to form a great deal of uniformly sized small particles/nanocrystals, which were subsequently assembled to uniformly sized aggregates. The $\mathrm{TiO}_{2}$ aggregates showed much better light scattering property, larger specific surface area and higher dye-loading than those of the commercial P25 TiO2 nanoparticles. In comparison with P25, the short current density $\left(\mathrm{J}_{\mathrm{sc}}\right)$ and dye-loading of DSC based the as-synthesized $\mathrm{TiO}_{2}$ aggregates increased by $33 \%$ and $62 \%$, respectively. As a result, the PCE of the DSC was up to $7.64 \%$. 

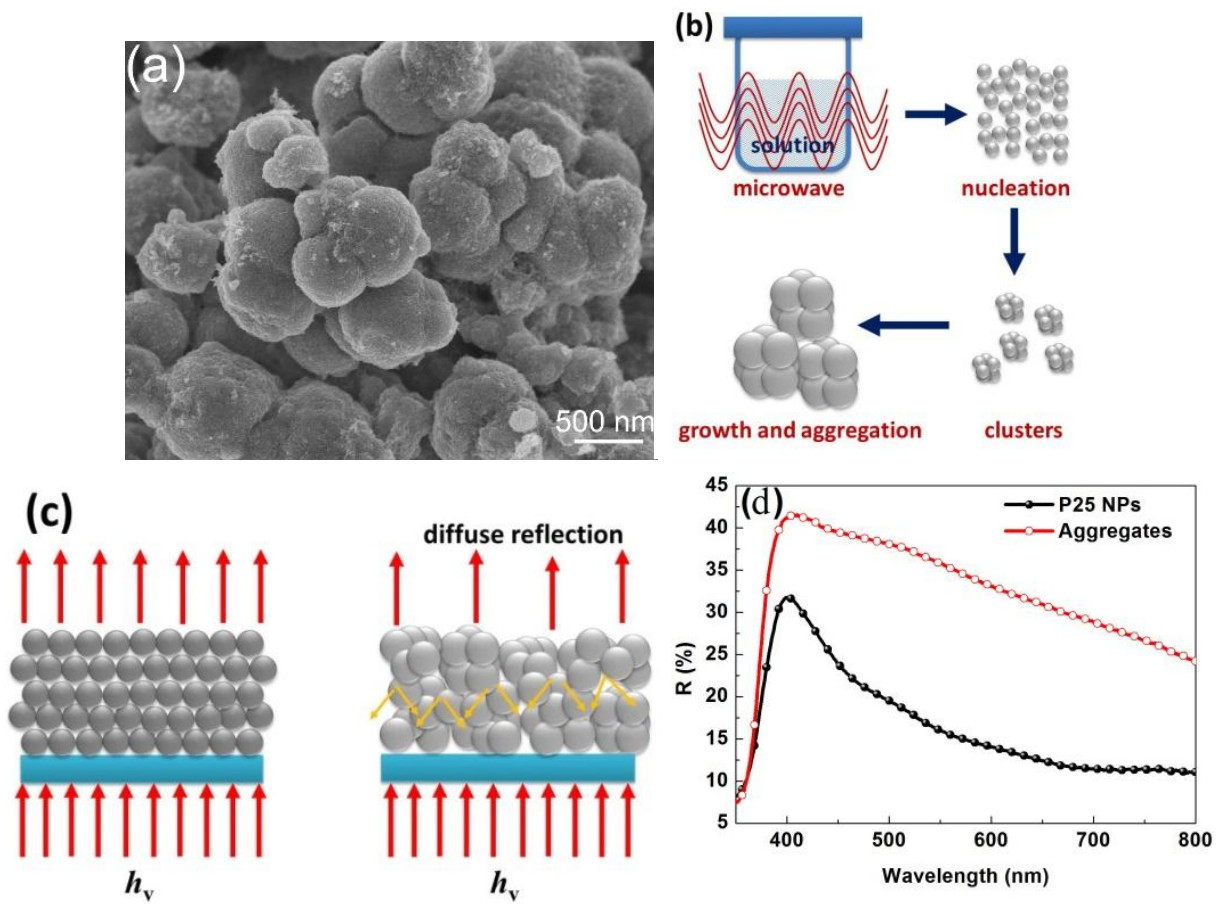

Figure 4. (a) $\mathrm{SEM}$ images of as-synthesized $\mathrm{TiO}_{2}$ aggregates, (b) schematic illustration of $\mathrm{TiO}_{2}$ aggregates formation process, (c) schematic illustration of the effect of the aggregates for the light scattering and (d) Diffuse reflection spectra curves of $\mathrm{P} 25$ nanoparticles $\mathrm{TiO}_{2}$ film and $\mathrm{TiO}_{2}$ aggregates film. Reprinted from reference [87].

It was also found that the electron diffusion in the $\mathrm{TiO}_{2}$ aggregate network was enhanced through the addition of $\mathrm{TiO}_{2}$ nanoparticles with preferential filling at the necks between adjacent $\mathrm{TiO}_{2}$ aggregates, which resulted in strengthening the connections, while retaining the porous structure of the $\mathrm{TiO}_{2}$ network as shown in Figure 5.[89] The fortified necks was found to reduce the transport resistance $\left(R_{t}\right)$ by allowing facile transfer of electrons from one aggregate to another, while the scattering effect of the $\mathrm{TiO}_{2}$ aggregate network got weakened with adding the $\mathrm{TiO}_{2}$ nanoparticles as a result of reduction of the light scattering centers such as the necks and gaps between the aggregates. However, due to the increase in surface area as the $\mathrm{TiO}_{2}$ nanoparticles were added, the diminished light scattering effect of the aggregate network was compensated and even the highest performance was achieved when the $10 \% \mathrm{TiO}_{2}$ nanoparticle was added into the $\mathrm{TiO}_{2}$ aggregate film, suggesting that widening necks between sub-micrometer sized light scatters such as an aggregate would be a good strategy in achieving further improvement of PCE of dye sensitized solar cells through the improved charge transport property. 


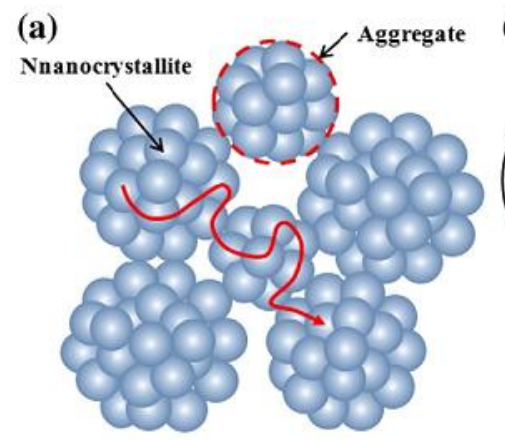

(b)

(c)
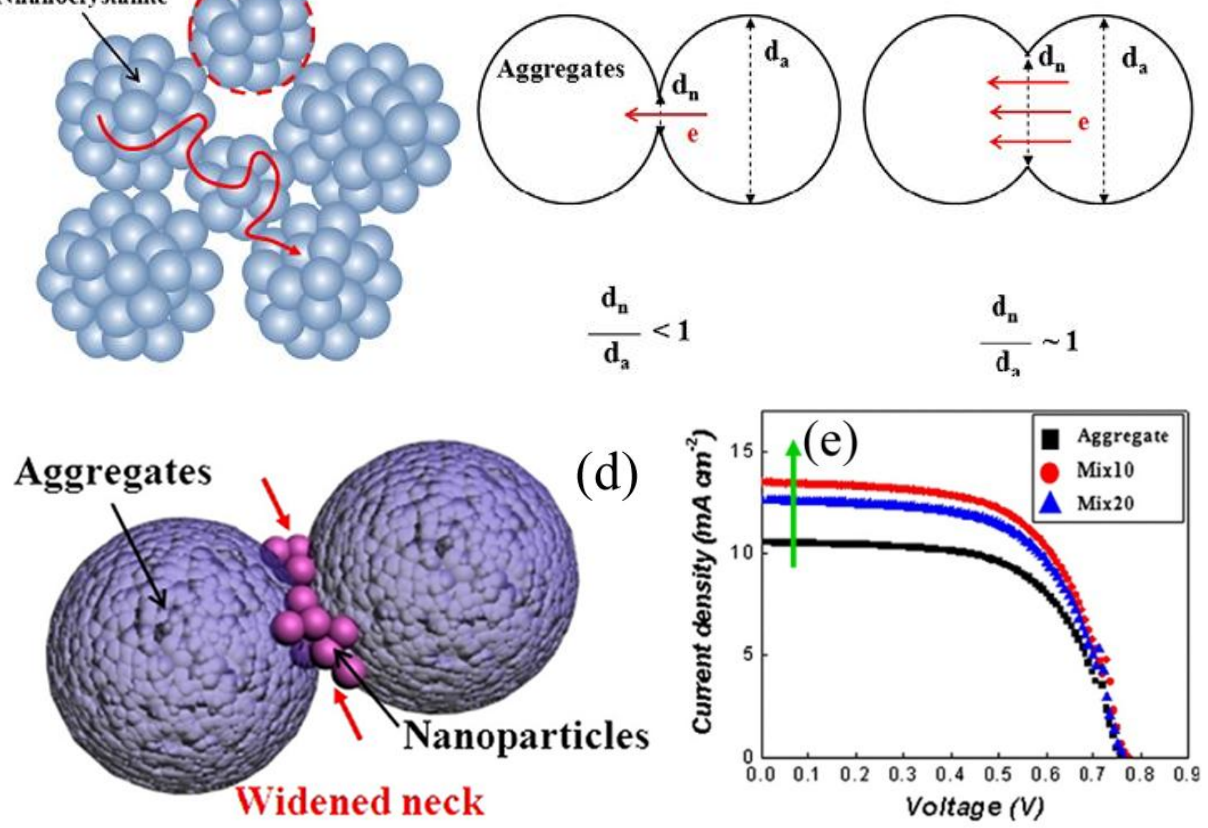

Figure 5. Schematics illustrating (a) electron diffusion in aggregates and through necks between aggregates, (b) low possibility of electron transfer from one aggregate to adjacent one due to poor neck, (c) high possibility of electron transfer as a result of widened neck compared to the diameter of the aggregate and (d) the widened neck between two aggregates achieved by filling with the added nanoparticles, (e) $\mathrm{J}-\mathrm{V}$ curves of the DSCs with the photoanodes composed of $\mathrm{TiO}_{2}$ aggregate and mixture of the aggreages and nanoparticles (Mix10 and Mix20). Reprinted from reference [88]. 

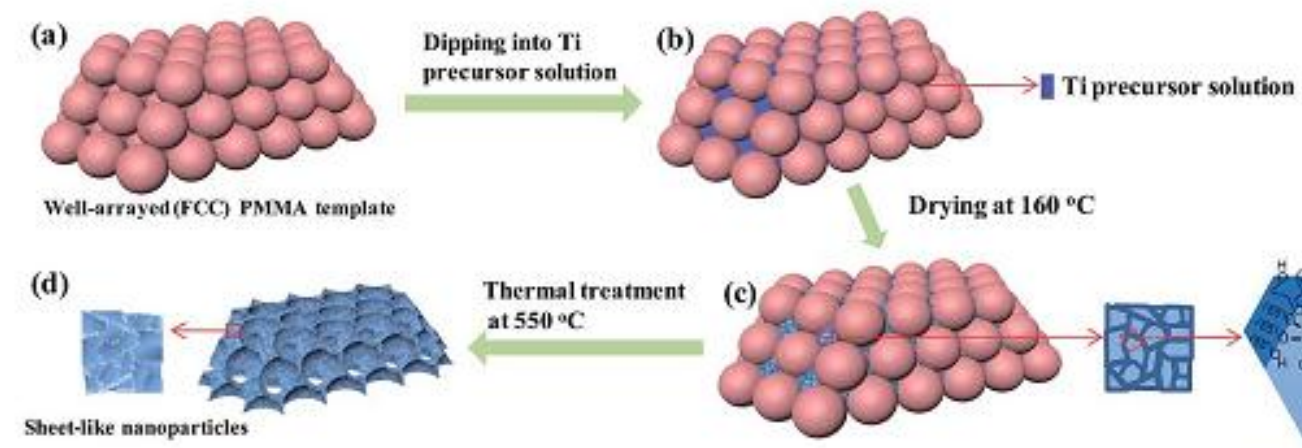

Thermal treatment at $5500^{\circ} \mathrm{C}$

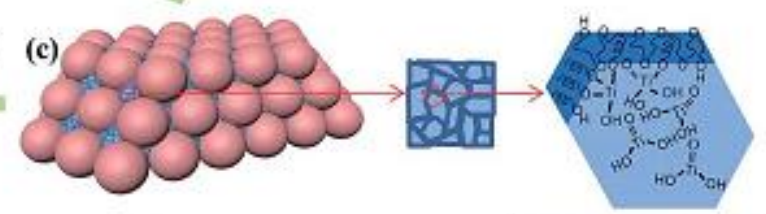

(e)
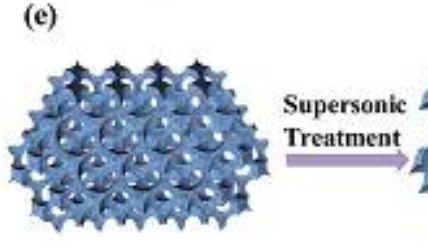

(f)
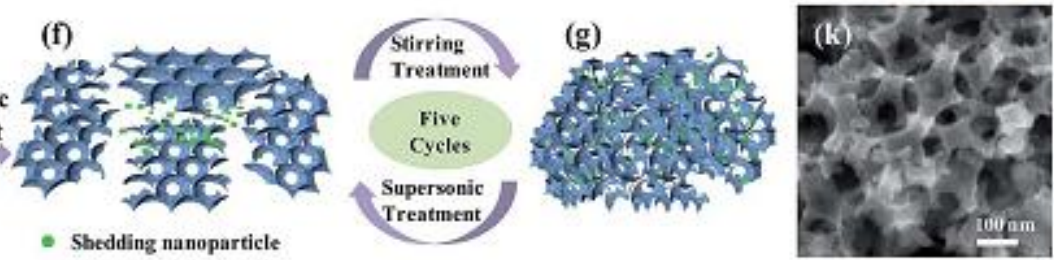

(h)

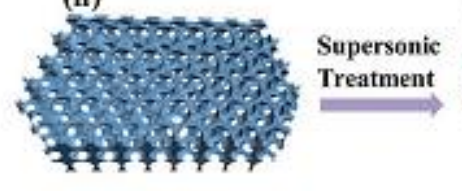

(i)

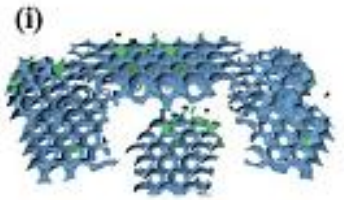

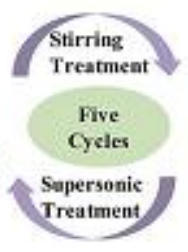
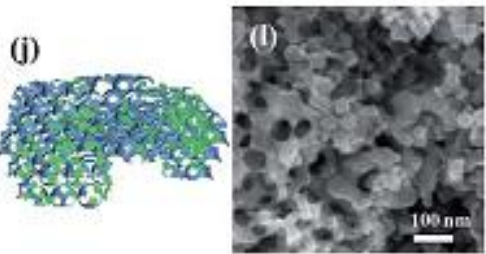

Figure 6. Schematic illustration of the paste formation process based on (a) Ti-155, Ti-155, and Ti-105 samples and the ones based on (c) Ti-85 sample, as well as HR-SEM pictures of photoanode films based on (k) Ti-105 and (1) Ti-85 samples. Reprinted from reference [89].

However, dye molecules and electrolyte are difficult to penetrate into the interior pores of the aggregates, which is not helpful for the improvement of enhanced photon capture and efficient transport of the photoexcited electron. The inverted aggregate hierarchical structure would have both high dye adsorption and strong light scattering. Our recent work reported a strategy for the synthesis of hierarchically structured three-dimensionally ordered macroporous (HS-3DOM) $\mathrm{TiO}_{2}$ with controlled macropore sizes (ca. $85-155 \mathrm{~nm}$ ) by using well-arrayed polymethyl methacrylate with different diameters as well as two kinds of photoanode films based on hierarchically structured porous $\mathrm{TiO}_{2}$ filled with nanoparticles have been demonstrated as shown in Figure 6 [90]. DSCs based on a special $\mathrm{TiO}_{2}$ photoanode with a macropore size of $105 \mathrm{~nm}$ exhibited a current density of 20.6 $\mathrm{mA} / \mathrm{cm}^{2}$ and a high PCE of $9.7 \%$. The hierarchically structured porous $\mathrm{TiO}_{2}$ layer has much large surface area to load dyes and high diffused reflectance and scattering to harvest photons, which is the main reason for high photo-generated current density. The results showed the electron lifetime was prolonged and charge recombination was reduced. This may be due to the special geometry architecture of the photoelectrodes. Therefore, this high PCE is ascribed to the special morphology of the $\mathrm{TiO}_{2}$ photoanode with high dye adsorption due to its ordered and 
open structures, and also its light scattering and charge collection efficiency.

\subsection{ZnO hierarchical structures for DSCs}

$\mathrm{ZnO}$ is known to have band structure and physical properties similar to that of $\mathrm{TiO}_{2}$, but a higher electron mobility than that of $\mathrm{TiO}_{2}[24,77,79]$. In additoion, $\mathrm{ZnO}$ with a hexagonal crystal structure possesses facets with different surface energy and, thus, can easily form anisotropic structures, such as nanorods, nanowires and nanoflowers, which enables it to exhibit unique electronic and optical properties [82, 91]. ZnO nanostructured photoelectrodes for DSCs have been investigated over the last several years [73, 74, 92, 93]. For ZnO based DSCs, the $\mathrm{ZnO}$ films with hierarchical structure have exhibited much better performance in DSCs than that of nanoparticles and 1-D structure, due to the larger specific surface area for dye-adsorption, effective light scattering within the photoanode, and more pores for the penetration of electrolyte into the photoanode films[76]. As early as 2008, we had prepared $\mathrm{ZnO}$ aggregates spheres made up of nanocrystallites for DSCs [79]. With increased dye-adsorption and light-scattering capabilities by the primary nanoparticles and secondary colloids, $5.4 \%$ of PCE was obtained, which is one highest PCE of ZnO based DSCs at that time. Recently, we develop a novel interface precipitation method to synthesize hierarchically structured $\mathrm{ZnO}$ nanocrystallite aggregates as shown in Figure 7 [76]. The conventional homogeneous precipitation process in aqueous solution is an efficient way to synthesize $\mathrm{ZnO}$ nanoparticles at low temperature. In this process, ethanol and water were used as solvents to first separately dissolve $\mathrm{NaOH}$ and zinc acetate dihydrate under stirring, respectively. The reaction occurred in the interface of the different solvents with a slow rate, which was easier to form a porous hierarchical structure. In comparison with $\mathrm{ZnO}$ nanoparticles synthesized by conventional homogeneous precipitation method, such hierarchical structure has larger specific surface area, more efficient dye-loading and effective light scattering within the photoelectrode; all result in an increased photocurrent. Furthermore, electrochemical impedance spectroscopy study revealed that reduced charge recombination in $\mathrm{ZnO}$ nanocrystallite aggregates resulted in enhanced Voc. As a result, a PCE of 5.07\% with commercially available dye N719 had been obtained without applying anti-reflection coating and chemical treatment, which was more than $200 \%$ of the PCE achieved in $\mathrm{ZnO}$ nanoparticles synthesized by homogeneous precipitation method in aqueous solution. 
(a)
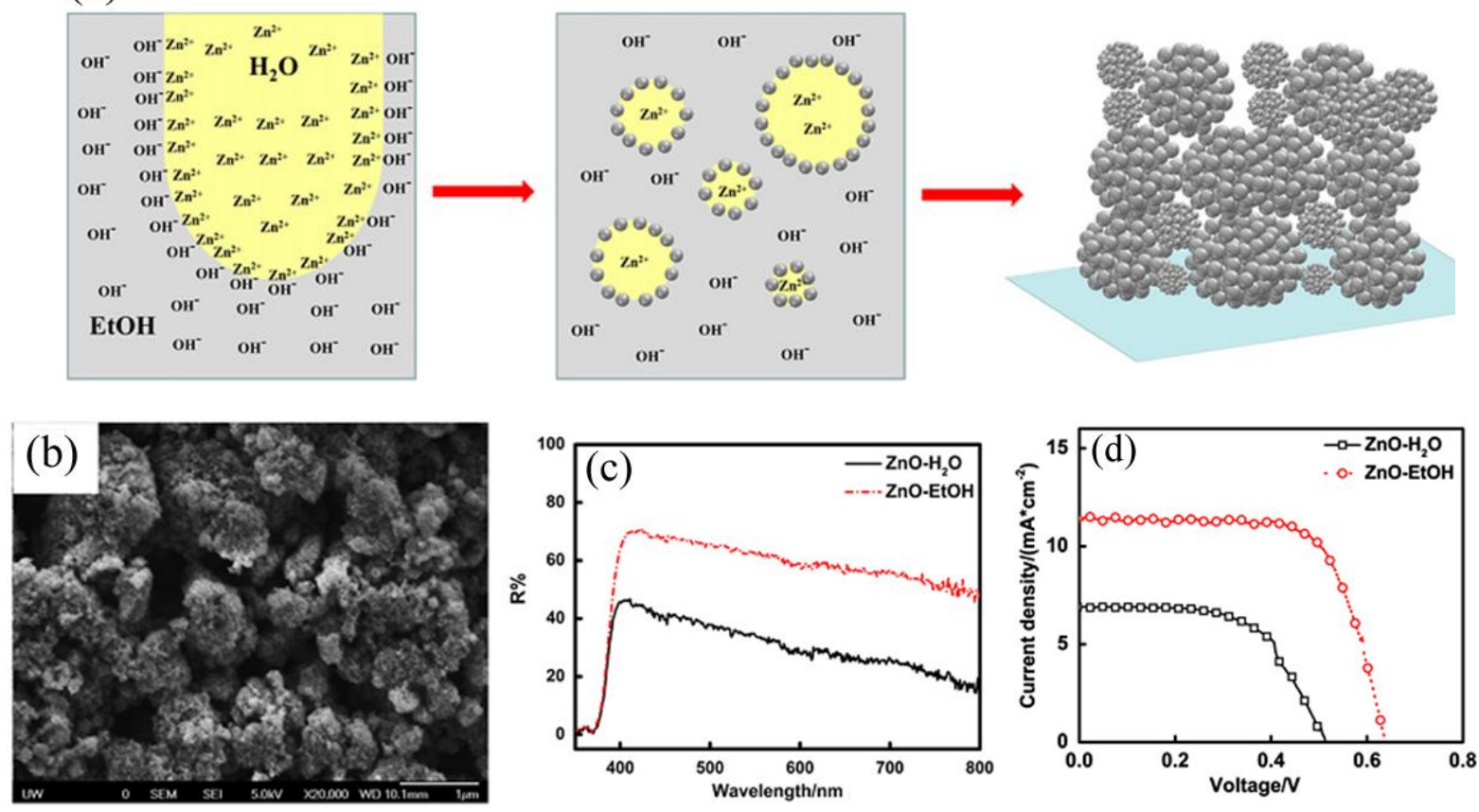

Figure 7. (a) schematic diagram of $\mathrm{ZnO}$ formation process using interface precipitation, (b) SEM image of $\mathrm{ZnO}$ aggregates, (c) diffuse reflectance of $\mathrm{ZnO}$ film prepared by different precipitation process and (d) J-V curves of DSCs based on the different $\mathrm{ZnO}$ photoanodes. Reprinted from reference [75]

A porous $\mathrm{ZnO}$ aggregates of nanocrystallites were thought to be helpful to retain their high surface area. However, their PCEs are still lower than that of $\mathrm{TiO}_{2}$ based DSCs, due likely to the poor chemical stability for dye solution and lots of surface defects for high charge recombination. A lot of research results showed that the charge recombination could be reduced by applying a core-shell configuration $[94,95]$. Such a core-shell configuration is expected to suppress the charge recombination by forming an energy barrier to prevent the electrons in the conduction band of the semiconductor from transferring to the oxidized dyes and ions in the electrolyte, leading to increased open circuit voltage and short current density[94-96]. It was also reported[92] that the shell $\left(\mathrm{TiO}_{2}\right)$ has a more negative conduction band edge than that of the core oxide $(\mathrm{ZnO})$ or it creates a dipole at the core - shell interface that shifts the band edge of the core upward in energy, which suppresses recombination and increases the open voltage and fill factor. Many novel core/shell structures, for example, $\mathrm{ZnO} / \mathrm{TiO}_{2}, \mathrm{ZnO} / \mathrm{Al}_{2} \mathrm{O}_{3}, \mathrm{ZnO} / \mathrm{ZrO}_{2}$ and $\mathrm{ZnO} / \mathrm{MgO}$ photoelectrodes, have been used in DSCs for this purpose [92, 94-97]. In an earlier study, atomic layer deposition (ALD) method was utilized to deposit ultrathin $\mathrm{TiO}_{2}$ layer on the porous structure of $\mathrm{ZnO}$ aggregates and, the resultant devices demonstrated much enhanced PCE of ZnO DSC with photoelectrodes made of submicrometer-sized aggregates of $\mathrm{ZnO}$ nanocrystallites as shown in Figure 8 [95]. The $\mathrm{ZnO}$ core/ $\mathrm{TiO}_{2}$ shell 
structure increases the open-circuit voltage, without impairing the photocurrent density and results in an increased PCE from $5.2 \%$ to $6.3 \%$.

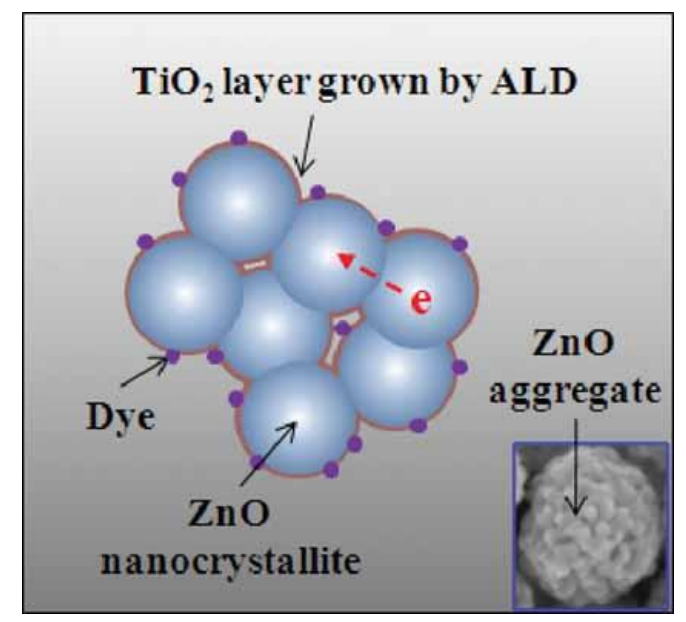

Figure 8. Schematics illustrating $\mathrm{ALD} \mathrm{TiO}_{2}$ thin layer on the surface of $\mathrm{ZnO}$ nanocrystallites, inset shows SEM image $\mathrm{ZnO}$ aggregate coated by $\mathrm{TiO}_{2}$ thin layer. Reprinted from reference [94]

ALD is rather time consuming and not cost effective [98]. Recently, a facile solution method was applied to modify the surface of $\mathrm{ZnO}$ aggregate photoandodes for DSCs as shown in Figure 9 [99]. During the modification process, the surface of the $\mathrm{ZnO}$ will be dissolved through a chemical reaction in an aqueous solution of $\left(\mathrm{NH}_{4}\right)_{2} \mathrm{TiF}_{6}$ and $\mathrm{H}_{3} \mathrm{BO}_{3}$, while the deposition of $\mathrm{TiO}_{2}$ nanocrystallites takes place sequentially and concurrently. This method can be considered as an in-situ alternative deposition method. As the chemical reaction on the surface of photoanode material is always easy to take place at an area with high surface energy, so $\mathrm{TiO}_{2}$ is more likely to deposit on the defect region of $\mathrm{ZnO}$ surface, which reduces the surface defects while further increases the surface stability [100]. The IPCE of the $\mathrm{TiO}_{2}$-modified film with a 3 min treatment exhibits a highest maximum to $60 \%$, whereas the film with a 20 min treatment shows a lowest maximum as shown in Figure 9 (c). The trend observed with IPCE matches with that of the $\mathrm{J}_{\mathrm{sc}}$, and the integrated current from the spectra correlates closely with the photovoltaic data. Figure 9 (d) displays the whole process of the photon-electric conversion in solar cells. Initially, the photons are captured by the dyes to realize the harvesting of light. Then, the electrons generated by dye will inject into photoanode. The energy difference between the lowest unoccupied molecular orbital (LUMO) of the dye and the conduction band of $\mathrm{TiO}_{2}$ provides driving force for charge injection. Therefore, the surface modification process introduces a thin layer of $\mathrm{TiO}_{2}$ nanoparticles on the surface of $\mathrm{ZnO}$ aggregates can reduce the charge recombination and increase the charge collection, at the same time, open the inner pores through in-situ selective etching of $\mathrm{ZnO}$ at pore apertures. As a result, the PCE of DSC was increased from $4.81 \%$ to $6.27 \%$, after 
surface modification of $\mathrm{ZnO}$ aggregates.
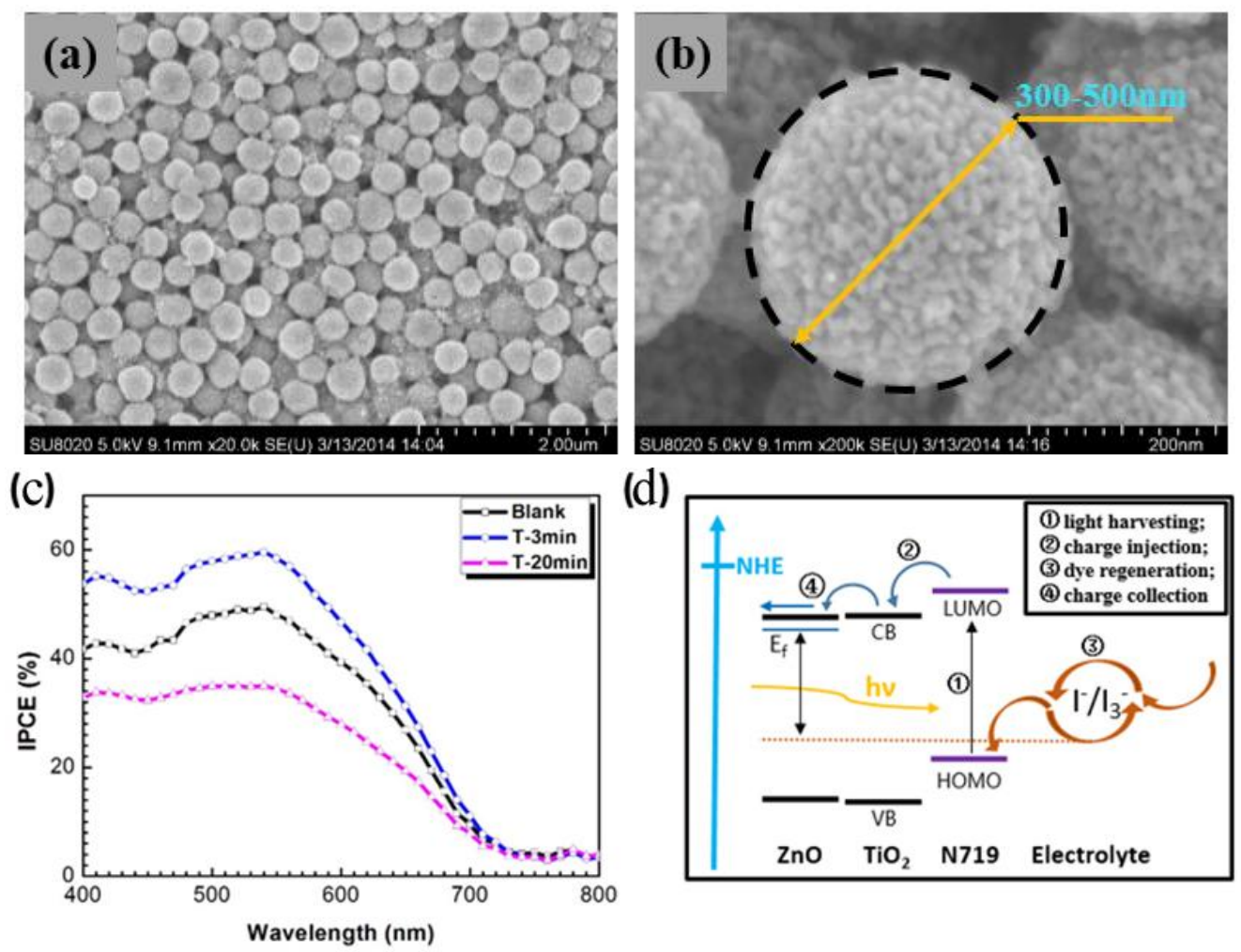

Figure 9. (a, b) SEM images of submicrometer-sized aggregates of $\mathrm{ZnO}$ nanocrystallites in different magnifications, (c) Incident photon-to-current conversion efficiency (IPCE) spectra of ZnO-based DSCs with different solution treatment times; (d) photoelectric conversion process in solar cells. Reprinted from reference [98]. 


\subsection{SnO2 hierarchical structures for DSCs}

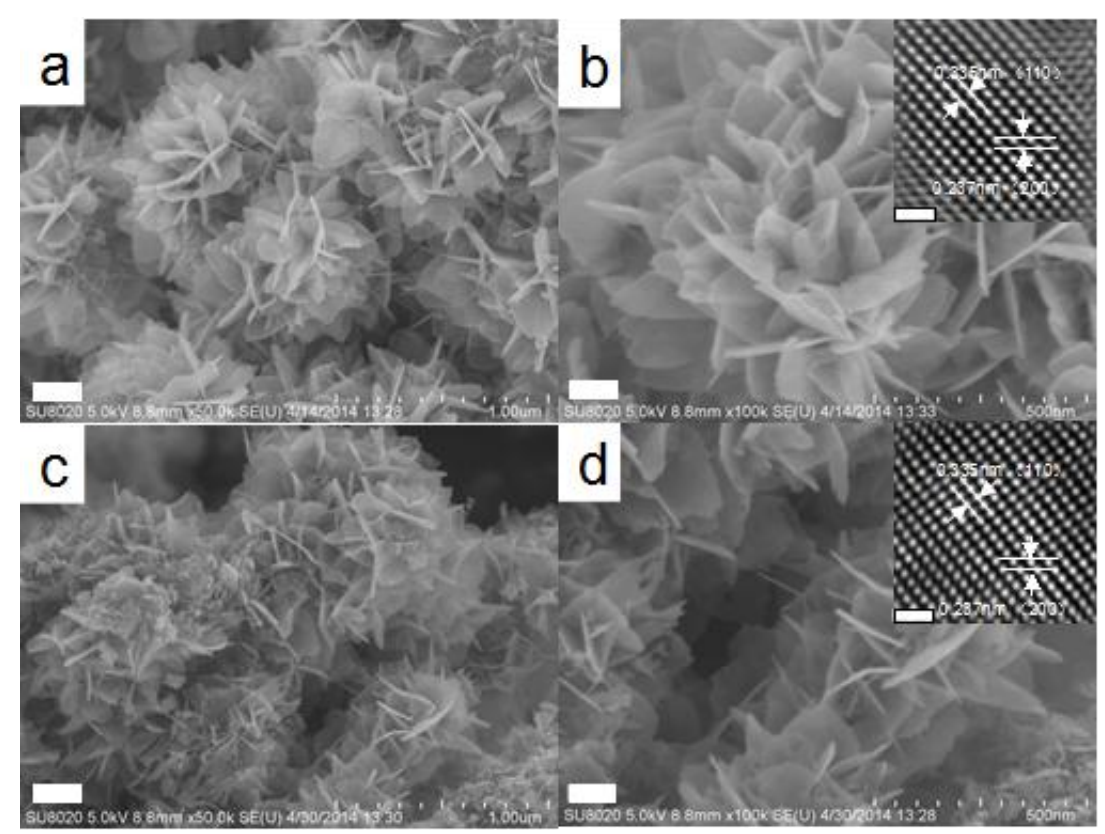

Figure 10. SEM images of (a), (b) $\mathrm{SnO}_{2}$ (hydrothermal) nanostructure and HRTEM images, inset, SEM images of (c), (d) $\mathrm{SnO}_{2}$ (microwave) nanostructure and HRTEM images, inset. The scale bars in SEM images of (a), (c) represent $200 \mathrm{~nm}$. The scale bars in SEM images of (b), (d) represent $100 \mathrm{~nm}$. The scale bars in HRTEM figures represent $1 \mathrm{~nm}$. Reprinted from reference [114].

$\mathrm{SnO}_{2}$ is an important n-type wide-bandgap semiconductor with wide applications in transparent conductive films, gas sensors, lithium-ion batteries, and solar cells [53, 101-105]. $\mathrm{SnO}_{2}$ as a possible alternative of $\mathrm{TiO}_{2}$ photoanode in DSCs with various morphologies, such as nanoparticles [106, 107], nanofibers [108], nanowires [109], nanotubes [110] and hollow nanospheres [111-114], have been successfully synthesized and characterized. For example, Cheng et al. [115] reported the synthesis of single-crystalline $\mathrm{SnO}_{2}$ nanorods with small size (15-20 $\mathrm{nm}$ in length and $2.5-5 \mathrm{~nm}$ in diameter) by hydrothermal treatment of $\mathrm{TiCl}_{4}$. Wu et al. [116] prepared 3D hierarchical $\mathrm{SnO}_{2}$ nanostructures composed of $2 \mathrm{D}$ nanosheets. $\mathrm{TiO}_{2}$-coated multilayered $\mathrm{SnO}_{2}$ hollow microspheres had achieved 5.65\% of PCE [117]. Among various techniques used for $\mathrm{SnO}_{2}$ synthesis, hydrothermal growth is one of the most common methods, which can form desired size and morphology by manipulating reactant ratio and reaction parameters [118]. Our recent work reported a microwave assisted synthesis of assembled $\mathrm{SnO}_{2}$ nanosheets and their characterization and application as photoanodes in DSCs as shown in Figure 10 [119]. The assembled $\mathrm{SnO}_{2}$ nanosheets photoanode, with large specific surface area, effective light-scattering and an easy path for electron transport with long lifetime, demonstrated appreciably increased 
short-circuit photocurrent density, reduced charge recombination and consequently high PCE. However, the limitations of $\mathrm{SnO}_{2}$ based DSCs are the relatively weak adsorption of the dyes with acidic anchoring groups, and the recombination of conduction band electrons with the oxidized dye [53]. In future, a lot of efforts should be focused on the surface and electronic modification of hierarchical $\mathrm{SnO}_{2}$ photoanodes to improve the PCE of DSCs.

\section{Quantum dot sensitized solar cells (QDSCs)}

QDSCs can be regarded as a derivative of DSCs, which use narrow-band-gap semiconductor quantum dots (QDs) photo-sensitizer instead of organic dyes in DSCs. Figure 11 shows the QDSC structure consists of a MOS photoanode, QDs (sensitizer), polysulfide electrolyte and counter electrode[64]. When the photons are harvested by QDs, the electron-hole pairs will be excited and then are rapidly separated into electrons and holes at interface between the MOS and QDs. The electrons are transferred by MOS, at same time, the holes are released by redox couples in the liquid electrolyte[37, 120]. The principles for choosing QDs and MOS photoanodes to construct QDSs are: (1) narrow and direct band gap QDs are preferred due to their high optical absorption, (2) MOS and QDs should have perfect matching in energy levels so that charges transport efficiently in the solar cells[8]. Table 2 shows the energy band parameters of QDs, which are usually chosen to fabricate QDSCs. Similar to DSCs, we can know that nanostructured MOS plays a key role in designing QDSCs. The difference between them is that the size of QDs is much larger than that of organic dye. The distribution and adsorbing capacity of QDs in MOS substrate are important issues for the performance of QDSCs. In this section, we will introduce and discuss our recent works on the fabrication of QDs, design and surface modification of $\mathrm{TiO}_{2}$ and $\mathrm{ZnO}$ MOSs to improve the performance of QDSCs.

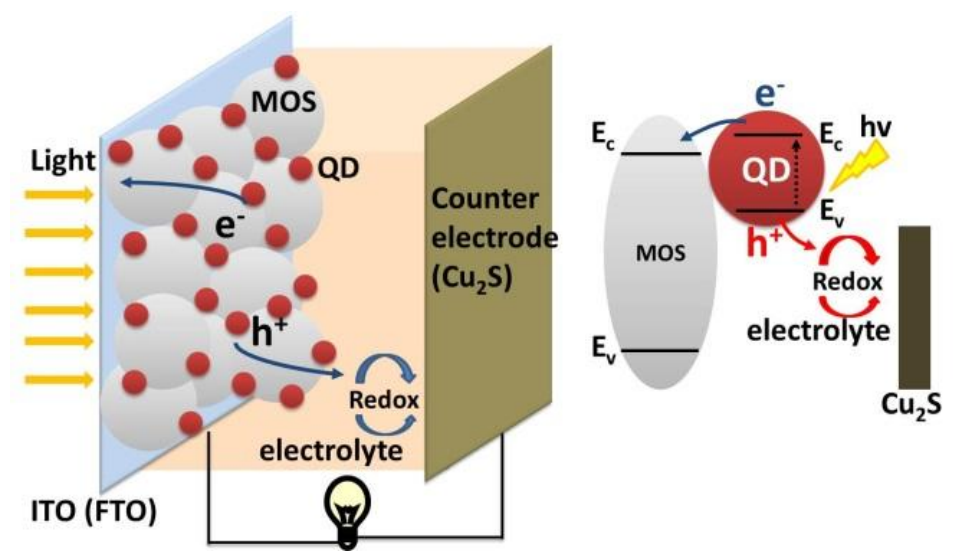

Figure 11. Schematic illustration of the structure of QDSC and photo-induced charge-transfer processes. Reprinted from reference [64] 
Table 2. Energy band parameters of some most commonly used QDs for QDSCs[121, 122] .

\begin{tabular}{cccc}
\hline Semiconductors & Band gap (eV) & $\begin{array}{c}\text { Conduction band } \\
\text { minimum }(\mathrm{eV})\end{array}$ & $\begin{array}{c}\text { Valence band } \\
\text { maximum }(\mathrm{eV})\end{array}$ \\
\hline $\mathrm{Ag}_{2} \mathrm{~S}$ & 0.92 & -4.5 & -5.42 \\
$\mathrm{CdS}$ & 2.40 & -3.98 & -6.38 \\
$\mathrm{CdSe}$ & 1.74 & -4.10 & -5.84 \\
$\mathrm{CuInS} S_{2}$ & 1.50 & -4.06 & -5.56 \\
$\mathrm{Cu}_{2} \mathrm{~S}$ & 1.10 & -4.44 & -5.54 \\
$\mathrm{PbS}$ & 0.37 & -4.74 & -5.11 \\
$\mathrm{PbSe}$ & 0.27 & -4.93 & -5.20 \\
$\mathrm{Sb}_{2} \mathrm{~S}_{3}$ & 1.72 & -4.72 & -6.44 \\
$\mathrm{SnS}_{2}$ & 2.10 & -4.44 & -6.54 \\
$\mathrm{SnS}$ & 1.01 & -4.66 & -5.67 \\
\hline
\end{tabular}

\subsection{Fabrication of QDs for QDSCs}

QDs are usually deposited onto mesoporous MOS films to form QDSCs electrodes via two approaches: (a) adsorption of pre-synthesized quantum dots, and (b) in-situ growth directly from the precursor solutions. The introduction of rapid injection of precursors into the reaction solvent at a certain temperature, called hot-injection synthesis, have been used to prepare colloid QDs since 1993 [123, 124]. This method has attracted much attention for QDSCs due to the advantages in using pre-synthesized monodispersed QDs of high crystallinity, with expectation to obtain overall control over the QD size, size distribution, and surface passivation. Recent years have witnessed the development of the post-synthesis assembly to fabricate high efficiency QDSCs, which generally involves three approaches: direct adsorption, electrophoretic deposition and linker-assisted deposition [125]. By exploiting this approach, $\mathrm{CdSe}_{\mathrm{x}} \mathrm{Te}_{1-\mathrm{x}}$ QDSCs with greater than 8\% of PCE was obtained in 2015 [42]. In-situ growth of QDs within the mesoporous MOS scaffolds, including chemical bath deposition (CBD)[126] and successive ionic layer absorption and reaction (SILAR)[36, 127], has shown highly photoelectric conversion efficiency when being adopted to assemble QDSCs[128]. The CBD is a relatively simple method to deposit QDs and nanoparticles films, which possesses many advantages, such as stable yields, robust adherence, uniform and good reproducibility. The growth of QDs strongly depends on the growth conditions, such as the duration of deposition, composition and temperature of the solution, and characteristics of the mesoporous films. The SILAR method is based on successive reactions on the surface oxides. Each reaction is followed by rinsing, which enables a heterogeneous reaction between the solid phase and the solvated ions in the solution. So a thin film can be grown layer by layer. In-situ growth method is regarded as a convenient, reproducible and cost-effective way to 
QDSCs. In addition, QDs can be adsorbed on the surface of MOS, which is helpful for injecting and transfer of photoexcited electron. We deposited $\mathrm{CdS}$ and CdSe QDs onto the mesoporous $\mathrm{TiO}_{2}$ film using SILAR and CBD, respectively, to form CdS/CdSe co-sensitized QD[37]. Figure 12 shows the schematic illustration of the formation process of CdS/CdSe QDs co-sensitized solar cells. The PCE of QDSC was up to 4.62\%.
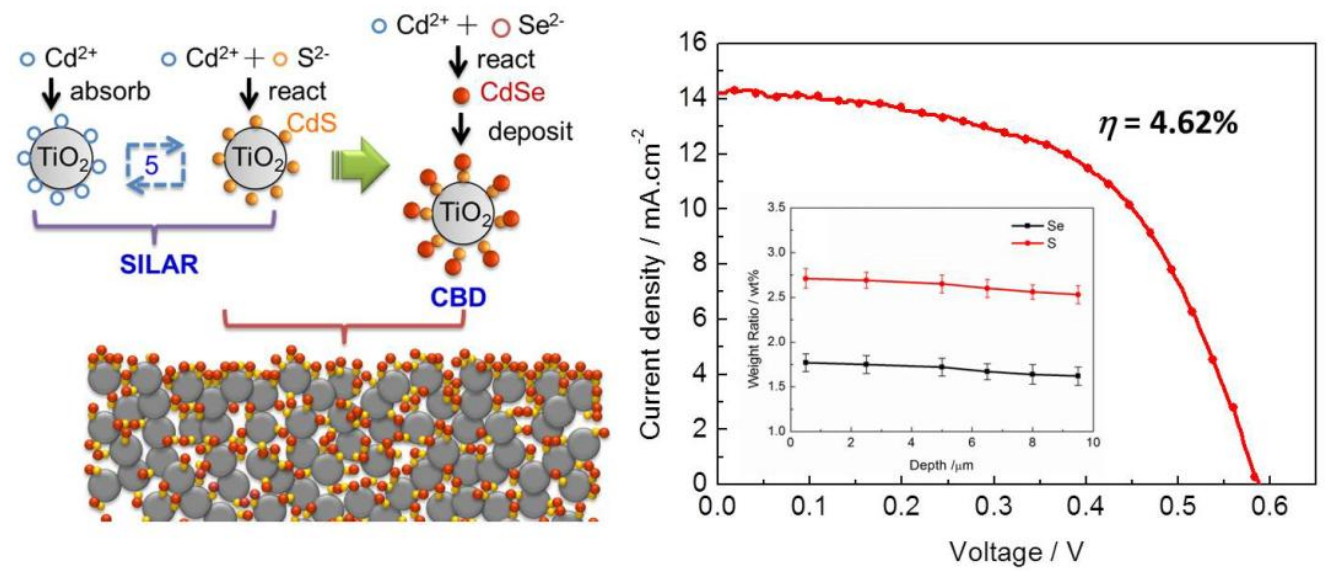

Figure 12. Sketch of the formation of $\mathrm{CdS} / \mathrm{CdSe}$ QDs on the mesoporous $\mathrm{TiO}_{2}$ film and J-V curve of QDSCs. Reprinted from reference [37].
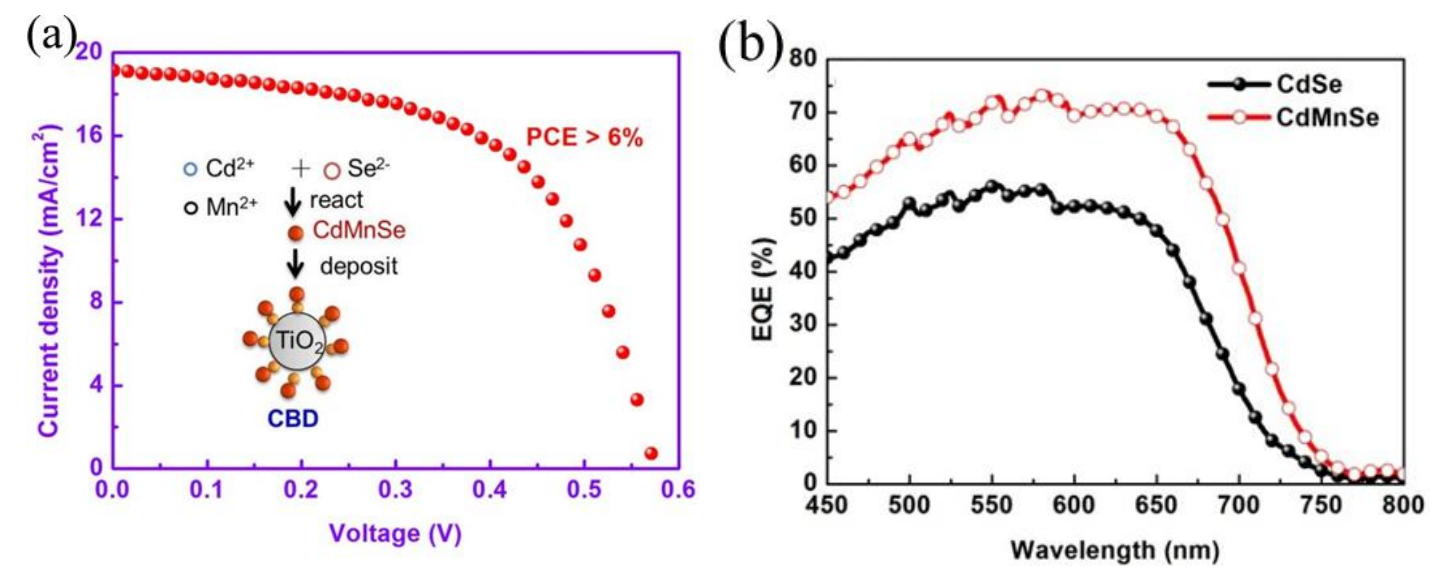

Figure 13. (a) J-V curve of CdMnSe QDSC, inset is the CBD process of CdMnSe QD; (b) external quantum efficiency (EQE) spectra curves of QDSCs. Reprinted from reference [38].

Recently, the method of using doping metal ions into QDs is thought an effective way to improve the performance of QDSCs. Some results, such as $\mathrm{Hg}^{2+}$ into $\mathrm{PbS}[129], \mathrm{Mn}^{2+}$ into $\mathrm{CdS}[130]$ and $\mathrm{Mn}^{2+}$ into $\mathrm{CdSe}[38]$, showed the increase of photo-electric properties of the solar cells. By using doping $\mathrm{Mn}^{2+}$ into $\mathrm{CdSe}$, we have successfully prepared a high efficiency of $6.33 \% \mathrm{Cd}_{0.8} \mathrm{Mn}_{0.2} \mathrm{Se}$ quantum dot solar cell using CBD method as shown in Figure 13[38]. The $\mathrm{Mn}^{2+}$ ions doped into QDs can increase the light harvesting to produce more excitons. In addition, $\mathrm{Mn}^{2+}$ dopant also raises the conduction band of CdSe, accelerates the electron injection 
kinetics and reduces the charge recombination to improve the charge transfer and collection. The increase of the efficiencies of light-harvesting, charge-transfer and charge-collection results in the improvement of the quantum efficiency of the solar cells.
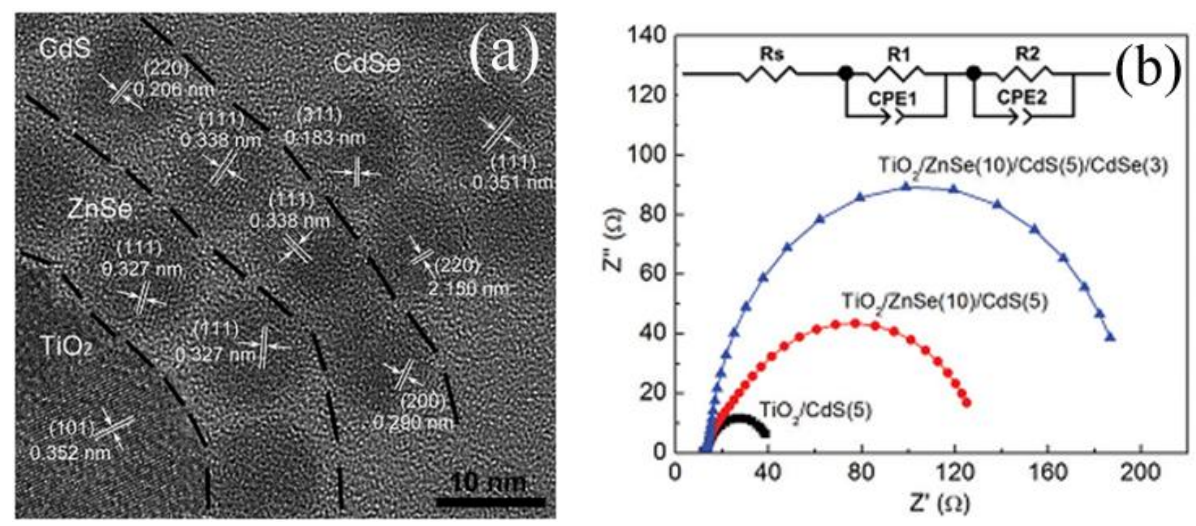

(c)

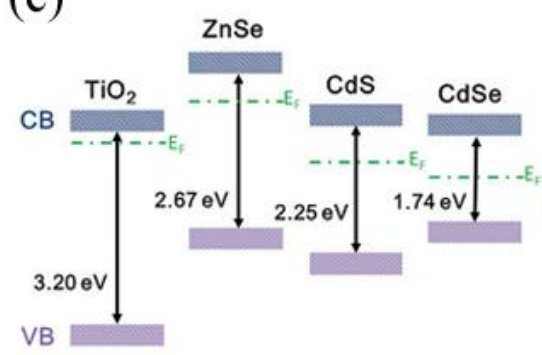

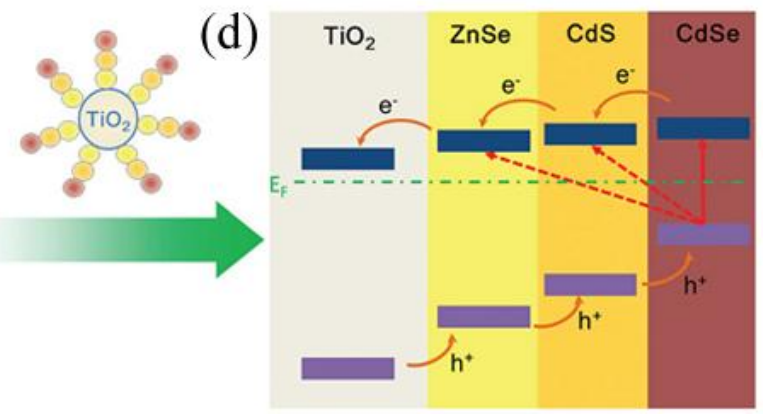

Figure 14. (a) HRTEM image showing the arrangement of $\mathrm{ZnSe} / \mathrm{CdS} / \mathrm{CdSe}$ QDs around a $\mathrm{TiO}_{2}$ crystallite and (b) Nyquist curves of the different layered QD-sensitized solar cell measured in the dark at $-0.6 \mathrm{~V}$ bias. (c) Relative band positions of $\mathrm{TiO}_{2}, \mathrm{ZnSe}, \mathrm{CdS}$, and CdSe in bulk and (d) ideal stepwise structure of band edges for the efficient transport of excited electrons and holes in a $\mathrm{TiO}_{2} / \mathrm{ZnSe} / \mathrm{CdS} / \mathrm{CdSe}$ photoelectrode. Reprinted from reference [126].

Inserting a layer of non-sensitized QDs on the surface of MOS phtoanodes not only helps to grow the subsequent sensitized QDs, but also suppresses the back charge recombination between the electrons in oxide and the holes in electrolyte. Recently, we prepared a multi-layered semiconductor ( $\mathrm{ZnSe} / \mathrm{CdS} / \mathrm{CdSe}$ ) QDs on the surface of $\mathrm{TiO}_{2}$ mesoporous films as shown in Figure 14 [131]. The multi-layered QDs-sensitized solar cells showed a larger short circuit currents and higher efficiency than those of single-layered QDs sensitized solar cells due to a complementary effect in light harvesting. Figure 14 (b) shows the recombination resistance is also increased by a seeding layer of $\mathrm{ZnSe}$, which leads the reduction of the charge recombination and the prolonging of the electron lifetime. The possible reason is that the cascade structure of multi-layered semiconductor is advantageous to the electron injection and hole recovery of QDs. The band edges and relative Fermi levels positions of $\mathrm{TiO}_{2}, \mathrm{ZnSe}$, 
$\mathrm{CdS}$, and $\mathrm{CdSe}$ in the bulk are schematically shown in Figure 14c. When $\mathrm{TiO}_{2}, \mathrm{ZnSe}, \mathrm{CdS}$ and $\mathrm{CdSe}$ are connected together, the difference in energy levels induces electron flow from the higher level (ZnSe) to the other lower levels. Therefore, the Fermi level of ZnSe would shift down with respect to the location of Fermi level in $\mathrm{TiO}_{2}$, and the conduction band edges of $\mathrm{CdS}$ and CdSe are elevated. Such electron transfer is known as the Fermi level alignment. The photoexcited electrons would transfer from the higher conduction band to the lower band with the help of a driving force. Therefore, the resulting conduction band edges for the $\mathrm{ZnSe} / \mathrm{CdS} / \mathrm{CdSe}$ device are inferred to have a stepwise structure, as shown in Figure 14d. The layer of ZnSe also acts as a blocking layer to shield the $\mathrm{TiO}_{2}$ core from the outer $\mathrm{CdS} / \mathrm{CdSe}$ QDs and electrolyte, and provides a physical separation of the injected electrons in $\mathrm{TiO}_{2}$ from the positively charged QDs and the electrolyte, thus retarding the interfacial recombination to obtain a high efficiency. As a result, the PCE was increase from 2.26\% for QDSC without ZnSe to $4.94 \%$ for QDSC with multi-layered QDs. So researchers may concentrate on designing more multi-layered QDs for QDSCs.

\subsection{TiO2 hierarchical structures for QDSCs}
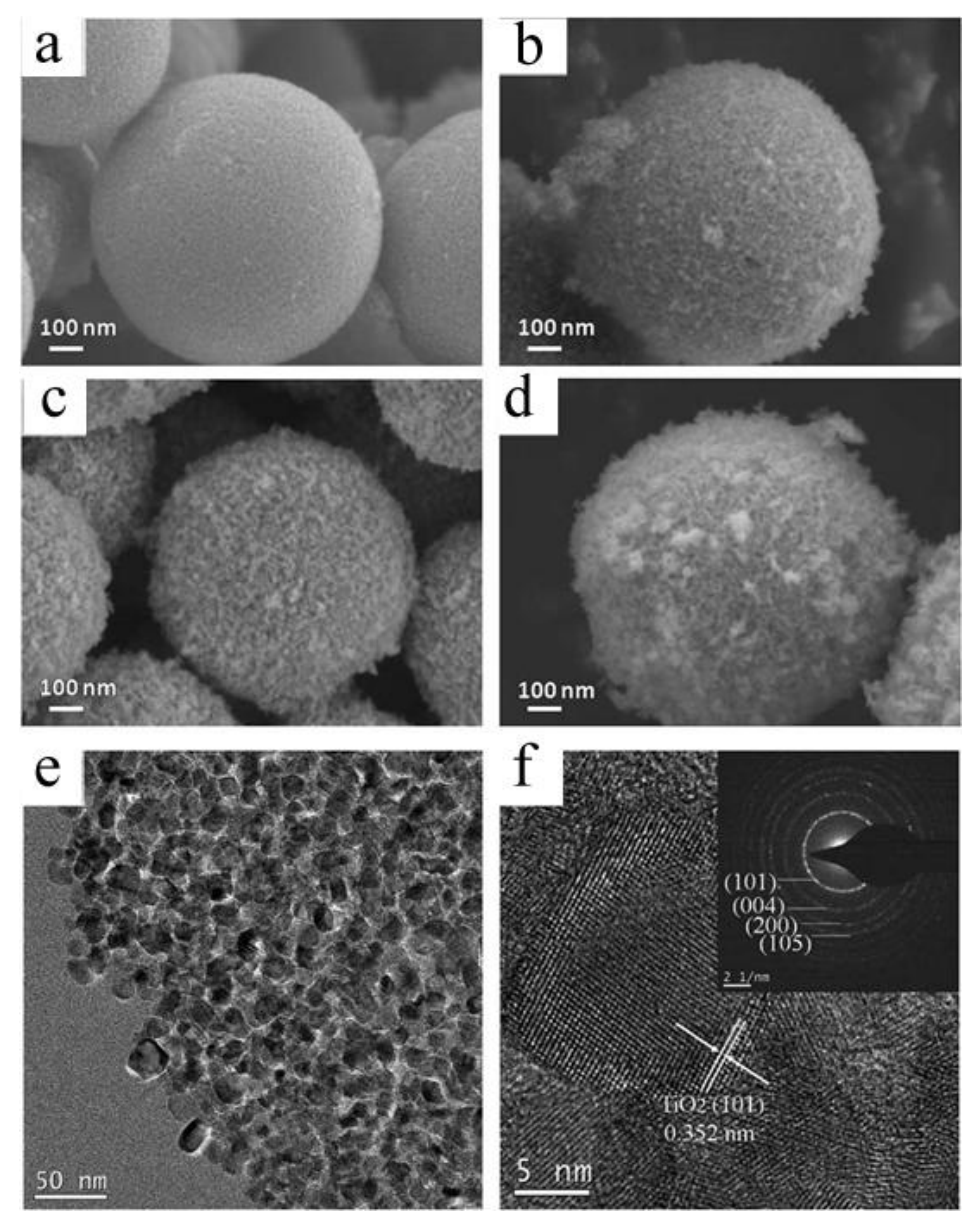

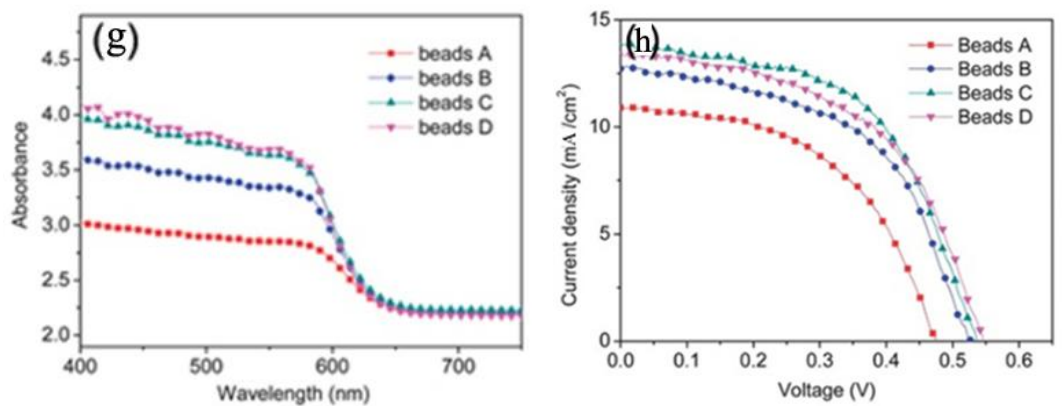

Figure 15. $\mathrm{SEM}$ image of $\mathrm{TiO}_{2}$ beads aggregates (a) $0 \mathrm{~mL}$, (b) $0.5 \mathrm{~mL}$, (c) $1 \mathrm{~mL}$ and (d) $2 \mathrm{~mL}$ ammonia solution; (e) TEM and (f) HRTEM images of the ultramicrotomed sample of the calcined mesoporous $\mathrm{TiO}_{2}$ beads without ammonia treatment during the solvothermal process. The inset of (f) shows the SAED pattern of $\mathrm{TiO}_{2}$ beads. (g) UV-Vis spectra of CdS/CdSe QDs co-sensitized $\mathrm{TiO}_{2}$ beads aggregates films, and (h) J- V curves for CdS/CdSe QDs co-sensitized solar cells using the photoanodes prepared by $\mathrm{TiO}_{2}$ beads aggregates. The beads prepared with the addition of $0,0.5,1$ and $2 \mathrm{~mL}$ ammonia to a mixture of $12 \mathrm{~mL}$ ethanol and $6 \mathrm{~mL}$ deionized water during the solvothermal treatment are denoted as beads A, B, C and D, respectively. Reprinted from reference [127].

The $\mathrm{TiO}_{2}$ aggregates film shows a better light scattering property to extend the light pathway for light harvesting, which has been used in DSCs in our previous works. Different from dye, QD is difficult to enter into the interior of the aggregates film due to their large size, which results in the low loading of QDs and poor performance of QDSCs. In order to dissolve this problem, we proposed a two-step fabrication method of $\mathrm{TiO}_{2}$ aggregates to increase the porosity of the aggregates [132]. The aggregate made of the mesoporous $\mathrm{TiO}_{2}$ beads has been prepared through a combined precipitation and solvothermal process. Figure 15 (a-d) shows SEM image of the mesoporous $\mathrm{TiO}_{2}$ beads aggregates. The aggregates were first synthesized using precipitation and solvothermal process. And then, an optimal amount of ammonia was adopted to etch $\mathrm{TiO}_{2}$ spheres and achieve the desired porosity of the beads for QDs adsorption. The ammonia etches the precursor aggregate beads to open the pore size of the aggregates. From Figure $15(\mathrm{~g})$, the absorbance of the films increases with increase of the addition ammonia, which followed the trend of increased pore size and pore volume but a decreased specific surface area. The properties of QDSCs are almost in accordance with the light absorbance of the aggregates (Figure 15 (h)). As a result, a PCE of the solar cell up to 4.05\% has been achieved for a CdS/CdSe QDSC. 


\subsection{Nanostructured ZnO for QDSCs}

\subsubsection{D nanostructured $\mathrm{ZnO}$ for QDSC}

It was demonstrated [37] that QDs experienced difficulty penetrating into the inner pores of the nanoparticles films, leading to several issues: (1) the direct exposure of MOS film in electrolyte resulting in a serious degree of recombination between the electrons in the MOS and holes in the electrolyte; (2) less QD loading in the films. Open structures, such as $1 \mathrm{D}$ structure of nanorods, nanowires and nanotubes, can facilitate the distribution of QDs from the surface to the interior of the films and enhance the QD loading. In addition, 1D structured MOS has a higher electron mobility than that of the nanoparticles. For $\mathrm{ZnO}$ nanowires, the electron diffusion coefficients $\left(D_{\mathrm{n}}\right)$ are $0.05-0.5 \mathrm{~cm}^{2} \mathrm{~s}^{-1}$, which are several hundred times larger than those of nanoparticle films. The electron diffusion coefficient determines the electron diffusion length as the following equation[12, 64]:

$$
L_{\mathrm{n}}=\sqrt{D_{n} \tau_{n}},
$$

where $L_{\mathrm{n}}$ is the electron diffusion length, $D_{\mathrm{n}}$ is the electron diffusion coefficient, and $\tau_{\mathrm{n}}$ is the electron lifetime. A longer diffusion length is typically associated to the higher charge collection efficiency. For QDSCs, such open structures of 1D MOS can also facilitate the permeation of QDs from the surface to the interior of the films. 1D nanostructure offers a straightforward path for the electrons and shorten their transport time inside MOS, and then reduces the charge recombination probability. So the 1D nanostructure array is considered the most promising candidate materials for QDSCs owing to its effective electron transport, which helps to collect photogenerated electrons [133]. However, QDSCs based on 1D structure have not reached a high conversion efficiency as expected due to the limited surface area for QDs adsorption. Introducing a surface profile modification for 1D MOS can be thought as an effective way to increase QD loading. Recently, we designed a facil surface modification process for $\mathrm{ZnO}$ nanowire arrays as shown in Figure 16 [134]. The $\mathrm{ZnO}$ nanowire arrays were fabricated by growing on seeded indium-doped tin oxide (ITO) substrate without using a template or high temperature conditions. After surface modification, the edges of the $\mathrm{ZnO}$ nanowires become "rough", which helps to harvest QDs as shown in Figure 16 (d). The surface modification method not only formed a barrier layer on the surface of the $\mathrm{ZnO}$ nanowire, which suppresses charge recombination by preventing the electrons in the $\mathrm{ZnO}$ conduction band from transferring to the oxidized ions in the electrolyte, but also modified the surface characteristics of the $\mathrm{ZnO}$ nanowire so as to harvest a greater amount of QDs and increase the short current density of the QDSC. PCE of QDSC was increased from $1.54 \%$ to $3.14 \%$ by surface modification. 

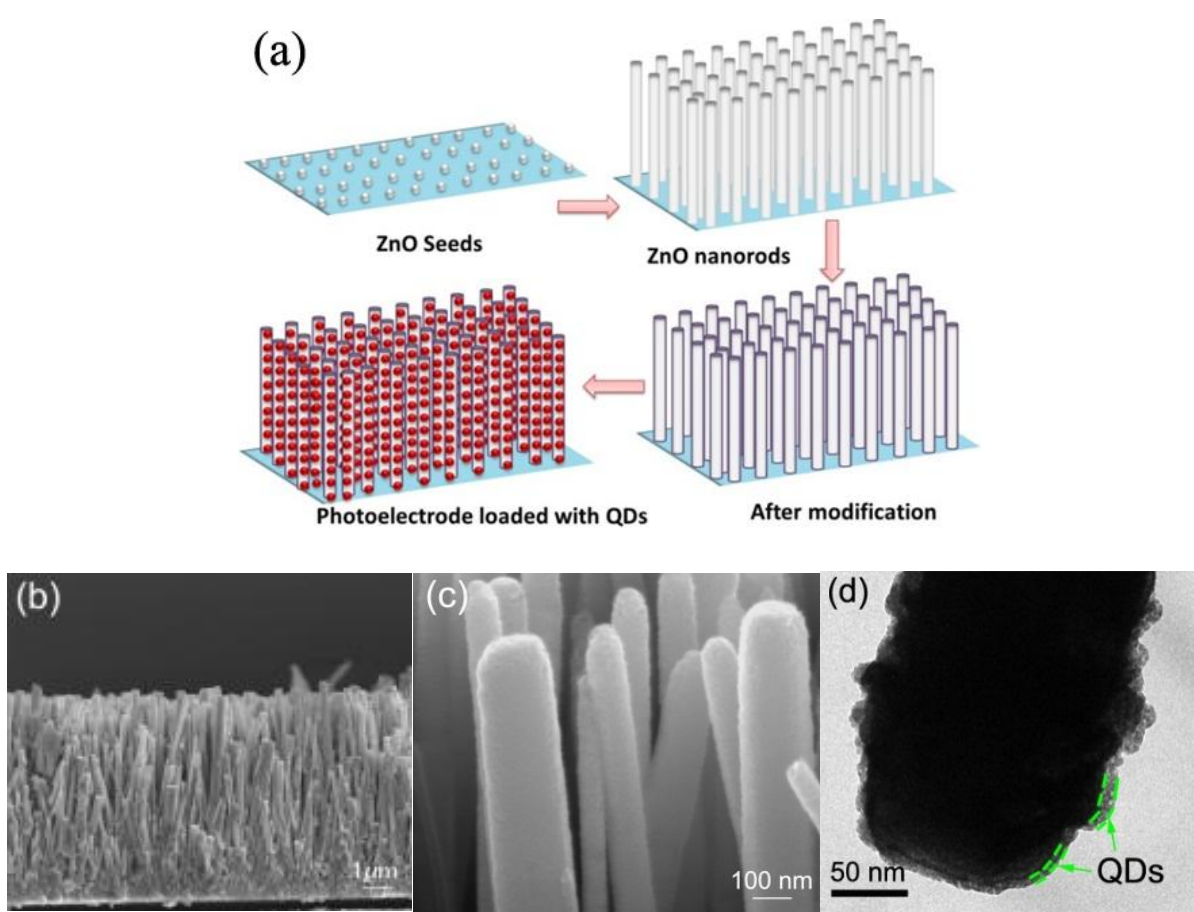

Figure 16. (a) Schematic illustration of the fabrication process of $\mathrm{ZnO}$ NR array photoelectrode for QDSC, (b) SEM images of ZnO NR array, (c) SEM image of modified ZnO nanorod array, (d) TEM image of ZnO nanorod coated by QDs. Reprinted from reference [129]

\subsubsection{Hierarchical nanostructured $\mathrm{ZnO}$ for QDSCs}

It is well-known that the surface area of photoanodes is a key factor for the loading of QDs. For 1D nanostructured MOS, a fundamental drawback is the insufficient internal surface area owing to a low roughness factor or the considerable free space between adjacent 1D nanostructures[135]. Hierarchical branched nanostructures are derived from 1D nanostructures however with a consideration to enlarge the surface area through using extended "branches"[12], which mainly include branched and dendritic nanowires or nanorods. Our recent work reported a $\mathrm{ZnO}$ nanorods branched by nanosheets for QDSCs as shown Figure 17 [136]. The thin $\mathrm{ZnO}$ nanosheets were slowly assembled on the surface of nanorods to form a hierarchically branched photoanode for constructing CdS/CdSe QDSCs. This branched structure had two advantages in improving the PCE of the solar cells: (a) it increased surface area and modified surface profile of the $\mathrm{ZnO}$ nanosheets to aid in harvesting more quantum dots (as shown Figure 17(g)), which leads to a high short current density $\mathrm{J}_{\mathrm{sc}}$; (b) it facilitated the transportation of the electrons in this compact structure to reduce the charge recombination, which led to the enhancement of $\mathrm{V}_{\mathrm{oc}}$ and FF. As a result, the QDSC assembled with the hierarchical photoanode exhibited a high PCE of 3.28\%, which is twice more than that of NRs photoelectrode (1.37\%). 

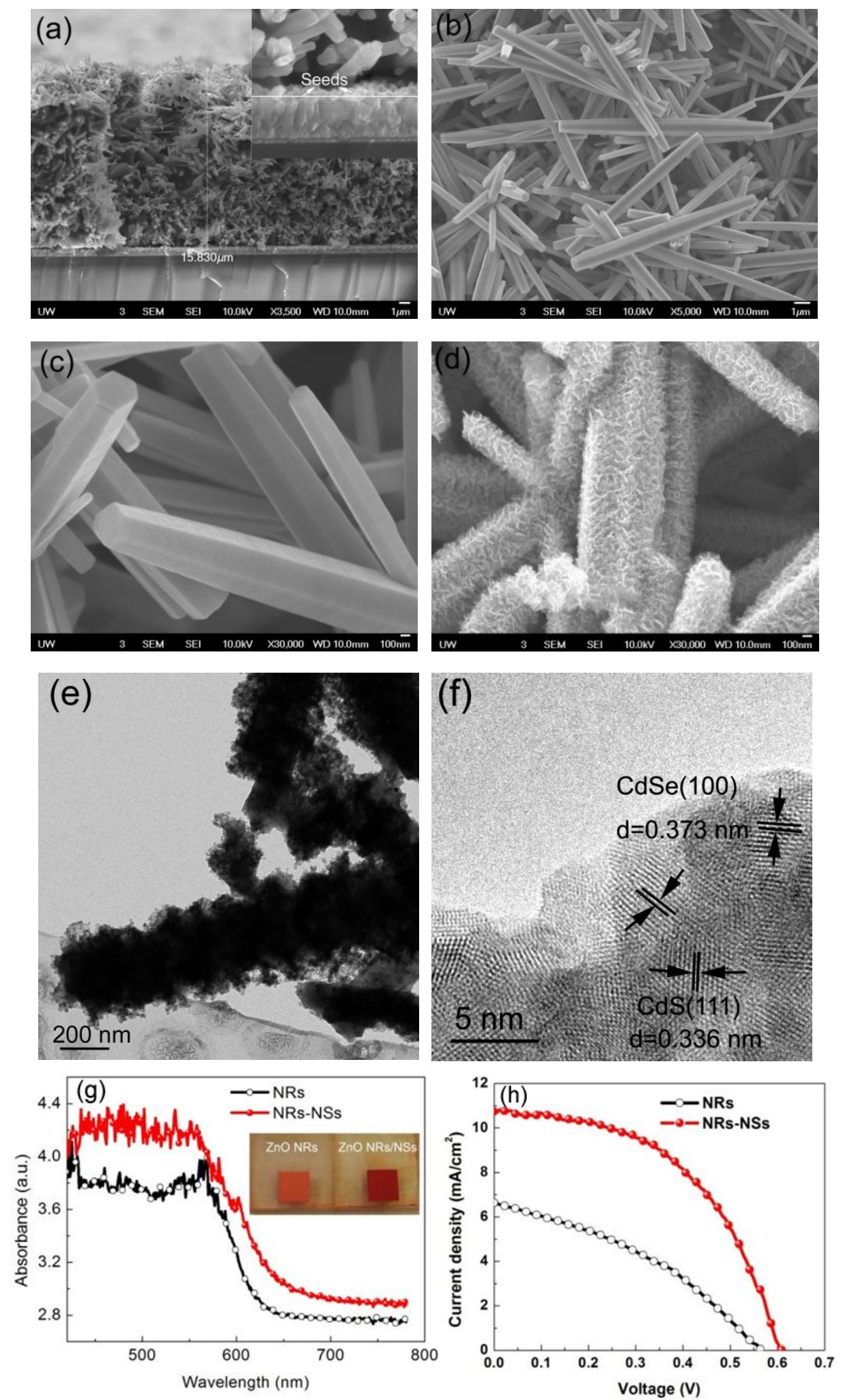

Figure 17. (a) SEM images of the cross section of the $\mathrm{ZnO}$ nanorods film, inset shows the cross section of the seed layer and nanorods film; (b) and (c) SEM images of $\mathrm{ZnO}$ nanorods, (d) SEM images of $\mathrm{ZnO}$ nanorods-nanosheets branched structure, (e) TEM and (f) HRTEM images of the branched ZnO loaded with QDs, (g) Optical absorbance spectra of the ZnO photoelectrodes loaded with QDs, and (h) J-V curves of QDSCs 
assembled with different photoelectrodes under simulated AM 1.5, $100 \mathrm{~mW} / \mathrm{cm}^{2}$ sunlight. Reprinted from reference [131].

Although ZnO hierarchical aggregates show good light scattering for QDSC, its PCE is much lower than that of nanoparticles. In order to utilize the light scattering of the aggregates, a bilayer structure was constructed by $\mathrm{ZnO}$ nanoparticles film and $\mathrm{ZnO}$ nanosheets aggregates scattering layer as shown in Figure 18 [137]. The growth orientations of $\mathrm{ZnO}$ crystals was controlled to form nanosheets, which attached together and assembled into aggregates due to the high surface energy of the nanosheets. The aggregates were used as a top layer to effectively increase the light diffuse reflection and harvesting to enhance photo-generated current (as shown Figure 18 (c)). In comparison with $\mathrm{ZnO}$ single nanoparticles film, the $\mathrm{J}_{\mathrm{sc}}$ of QDSC assembled by $\mathrm{ZnO}$ bilayer structure is increased from $10.3 \mathrm{~mA} / \mathrm{cm}^{2}$ to $16.0 \mathrm{~mA} / \mathrm{cm}^{2}$, which represents an enhancement of $55 \%$. Such structured QDSC exhibited a high PCE of 5.08\%.
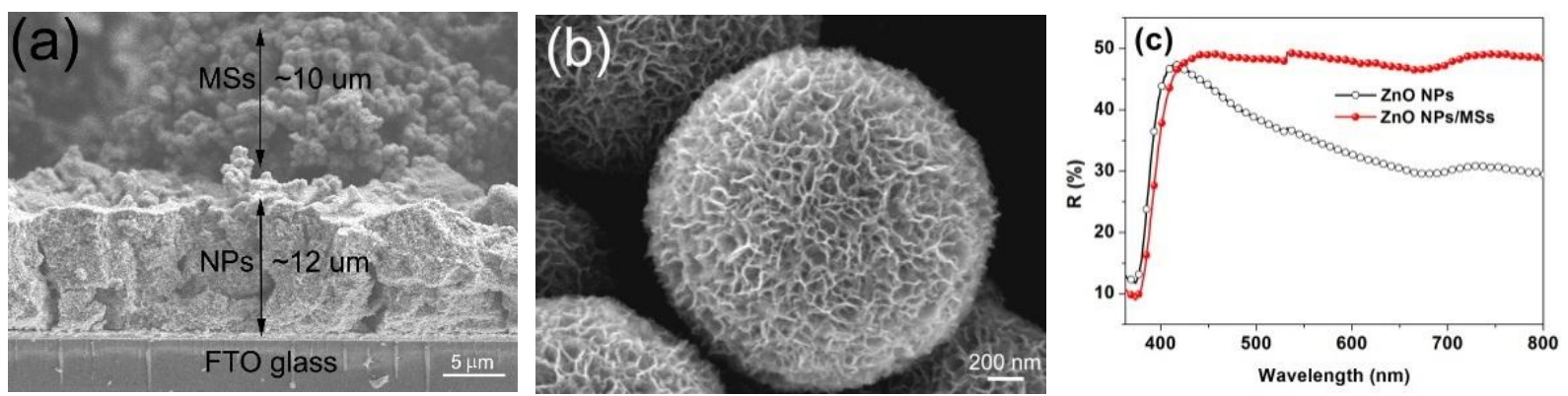

Figure 18. (a) SEM image of the bilayer structure composed of ZnO NPs film and NSs aggregates layer, (b) SEM image of the $\mathrm{ZnO} N S s$ aggregate, and (c) diffuse reflection spectra curves of $\mathrm{ZnO}$ films. Reprinted from reference [132].

\subsubsection{Surface modification of ZnO for QDSCs}

Nanostructured $\mathrm{ZnO}$ faces two questions: (1) instability in the electrolyte; (2) a large amount of surface defects. For $\mathrm{ZnO}$ based QDSCs, the surface charge recombination is limit factor for improving the performance of the devices. The processes of charge recombination in QDSCs is somewhat different to DSCs, which can be simplified as shown in Figure 19. There are seven pathways of recombination in QDSCs [64]: (1) recombination of electrons in the QD conduction band and holes in the QD valence band; (2) recombination of electrons with the electron acceptors in the electrolyte; (3) trapping of the exited electrons at the surface states of QDs; (4) 
trapping of the free electrons at the a surface states of QDs; (5) back electron injection from $\mathrm{ZnO}$ to QDs; (6) trapping of the free electrons at the interface states of $\mathrm{ZnO}$ particles and (7) back electron injection from $\mathrm{ZnO}$ to the electrolyte. The electron quenching (1)), recombining with the electrolyte ((2)), trapping (3) and (4)) strongly depend on the surface quality of QDs. The pathways (5), (6) and (7) relate directly to the interfaces state of $\mathrm{ZnO}$. Therefore, a lot of interfaces in the nanostructured $\mathrm{ZnO}$ provide easy pathways for charge recombination. The state of adjacent surface between QDs and $\mathrm{ZnO}$ also propels the free electron trapping. The introduction of surface modification for $\mathrm{ZnO}$ is believed to be an effective approach for decreasing the charge recombination and improving the transports of the electrons or holes[59]. For example, the surface modification for $\mathrm{ZnO}$ can increase the interfacial resistance and decrease the surface defects, which results in the recombination reduction through the mechanisms (4), (5), (6) and (7). In addition, the surface modification can also change the surface energy of $\mathrm{ZnO}$ for loading more QDs[138].

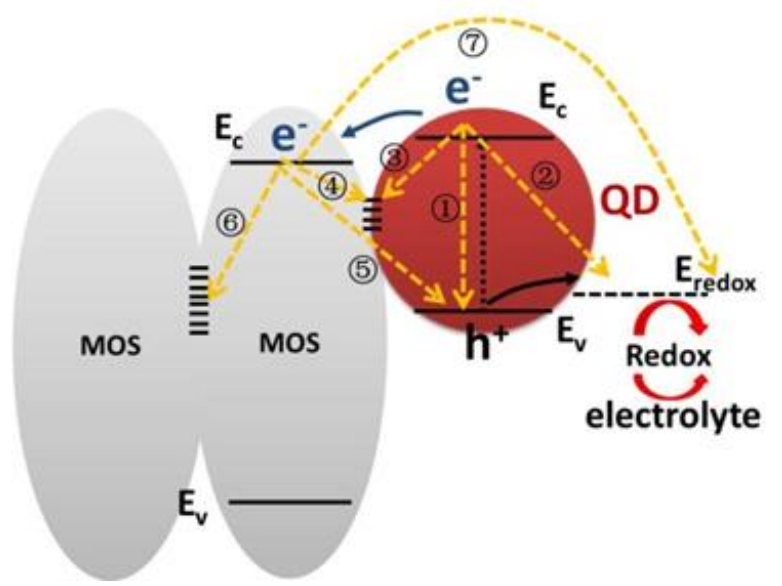

Figure 19. Schematic illustrations of charge recombination processes in QDSCs. Reprinted from reference [64].

However, the introduction of shell layer on the $\mathrm{ZnO}$ surface will reduce the porosity of the $\mathrm{ZnO}$ film, which could result in the decrease of the loading of QDs. Recently, we develop a facile chemical passivation strategy for $\mathrm{ZnO}$ mesoporous photoelectrode, which not only enlarged the apertures in the $\mathrm{ZnO}$ mesoporous photoelectrode to harvest more QDs, but also introduced a thin $\mathrm{TiO}_{2}$ nanoparticle layer on the surface of $\mathrm{ZnO}$ to decrease the surface charge recombination [139]. The process can be expressed via the following equations [139, 140]:

$$
\begin{aligned}
\mathrm{TiF}_{6}^{2-}+2 \mathrm{H}_{2} \mathrm{O} \leftrightarrow \mathrm{TiO}_{2}+6 \mathrm{~F}^{-}+4 \mathrm{H}^{+} \\
\mathrm{H}_{3} \mathrm{BO}_{3}+4 \mathrm{H}^{+}+4 \mathrm{~F}^{-} \leftrightarrow \mathrm{BF}_{4}^{-}+\mathrm{H}_{3} \mathrm{O}^{+}+2 \mathrm{H}_{2} \mathrm{O} \\
\mathrm{ZnO}+2 \mathrm{H}_{3} \mathrm{O}^{+} \rightarrow \mathrm{Zn}^{2+}+3 \mathrm{H}_{2} \mathrm{O}
\end{aligned}
$$

The reaction (2) and (3) can be shifted to the right by reaction (4), which indicates the dissolution of $\mathrm{ZnO}$ can 
boost the hydrolyzation of $\mathrm{TiF}_{6}{ }^{2-}$. Figure 20 (a) shows the variation of pore size, porosity and surface area of the film during the passivation process. $\mathrm{ZnO}$ is dissolved by reacting with $\mathrm{H}_{3} \mathrm{O}^{+}$so as to open the apertures and pores, at same time, $\mathrm{TiO}_{2}$ particles are deposited on the fresh surface and combine with the newly broken chemical bonds to form a passivation layer. Figure 20 (b) illustrates the recombination pathways of QDSCs. The passivation layer can increase the interfacial resistance and lead to recombination reduction through decreasing the back electron injection from photoanode to electrolyte. According to the results of electrochemical impedance spectroscopy (EIS) and light absorbance as shown in Figure 20 (c-e), both of QDs loading and electron lifetime have been improved by the surface modification. The PCE of QDSC is also increased from $2.38 \%$ to $4.68 \%$, almost doubled the PCE.

(a)
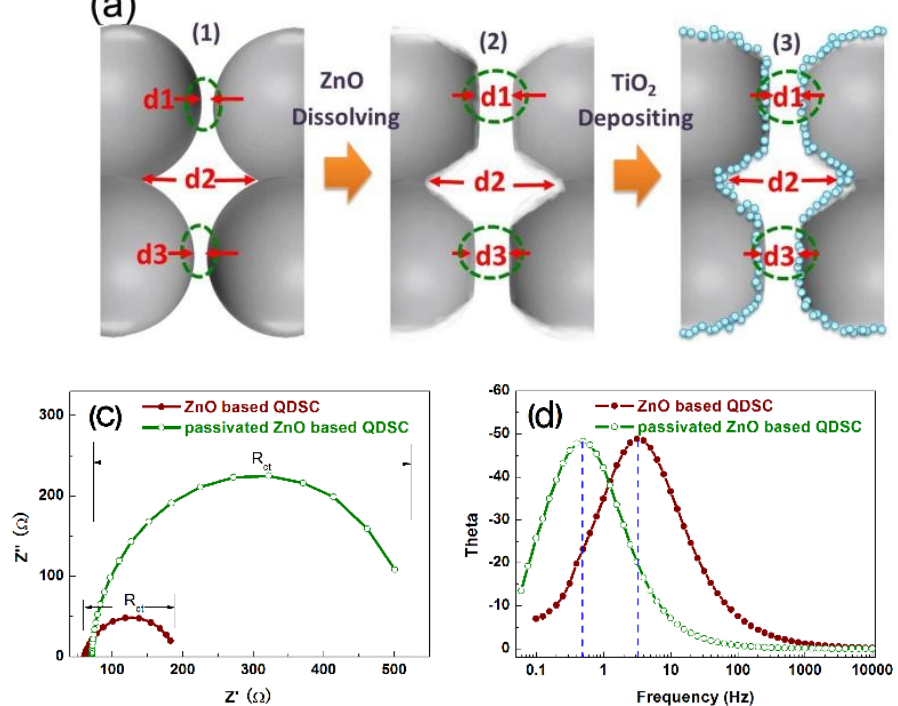
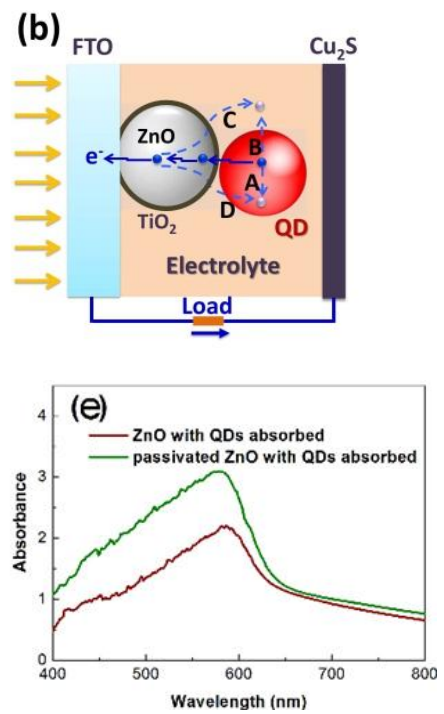

Figure 20. (a) Passivation process of the $\mathrm{ZnO}$ mesoporous film, (b) surface charge recombination pathways of the QDSC, (c) Nyquist plots curves and (d) bode plot curves of the QDSCs under forward bias (-0.6V) and dark condition, and (e) UV-Vis spectra curves of the $\mathrm{ZnO}$ films loaded with QDs. Reprinted from reference [134].

\section{Perovskite solar cells (PSCs)}

Organic-inorganic hybrid perovskite is a star material for the solar cells. In 2012, there are only several articles of PSCs. But the amounts of the publications of PSCs are more than 600 in the half year of 2015. In fact, the hybrid perovskites $\left(\left(\mathrm{C}_{4} \mathrm{H}_{9} \mathrm{NH}_{3}\right)_{2} \mathrm{PbI}_{4}, \mathrm{CH}_{3} \mathrm{NH}_{3} \mathrm{PbI}_{3}, \mathrm{CH}_{3} \mathrm{NH}_{3} \mathrm{SnI}_{3}\right.$, etc. $)$ had been synthesized several decades ago, which were widely used in organic light-emitting diodes due to high electrical mobility and good optical properties [141]. The band-gap of the perovskite $\mathrm{CH}_{3} \mathrm{NH}_{3} \mathrm{PbI}_{3}$ is $1.5 \mathrm{eV}$, which is very close to the Shockley-Queisser limit optimal band-gap $(1.34 \mathrm{eV})$ for solar cells[142]. So the perovskite $\mathrm{CH}_{3} \mathrm{NH}_{3} \mathrm{PbI}_{3}$ is an 
excellent potential light absorber material for the solar cell. There are two structures of PSCs: perovskite-sensitized solar cell and planar heterojunction perovskite solar cell as shown in Figure 21 [143]. Perovskites were first employed as 'sensitizers' on mesoporous $\mathrm{TiO}_{2}$ and their function in the solar cell was assumed to be analogous to the dye in DSCs (as shown in Figure 21 (a))[44, 143]. In this case, the working principle is expected to be similar to DSCs. However, the working mechanism is different from DSCs, because of charge transport and charge accumulation properties in the perovskite [45]. So the structure of the solar cell can be evolved into a simple planar heterojunction architecture, where a solid intrinsic perovskite layer is sandwiched between p- and n-type selective contacts ( as shown in Figure 21 (b)) [143].
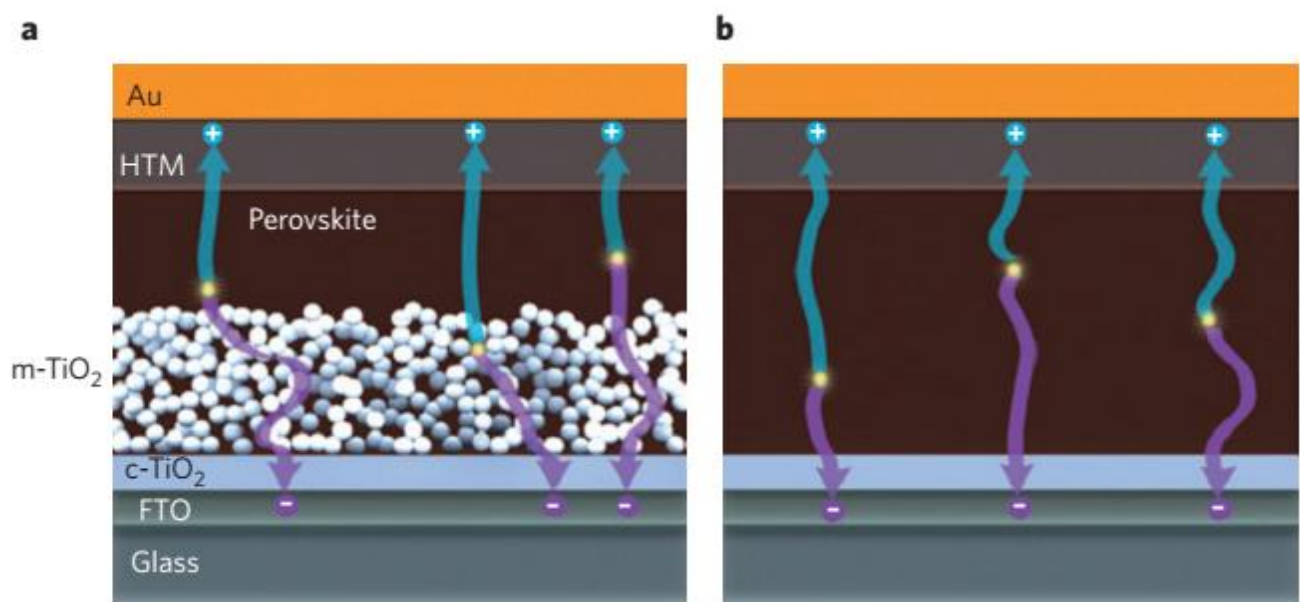

Figure 21. Illustration of the charge generation processes in a 'perovskite-sensitized' solar cell (a) and a planar heterojunction perovskite solar cell (b). $\mathrm{m}-\mathrm{TiO}_{2}$ and $\mathrm{c}-\mathrm{TiO}_{2}$ denote mesoporous and compact $\mathrm{TiO}_{2}$ layers, respectively, HTM (hole transport material) is the hole transporter material, and FTO (F-doped tin oxide) is the transparent conducting oxide. Reprinted from reference [132].
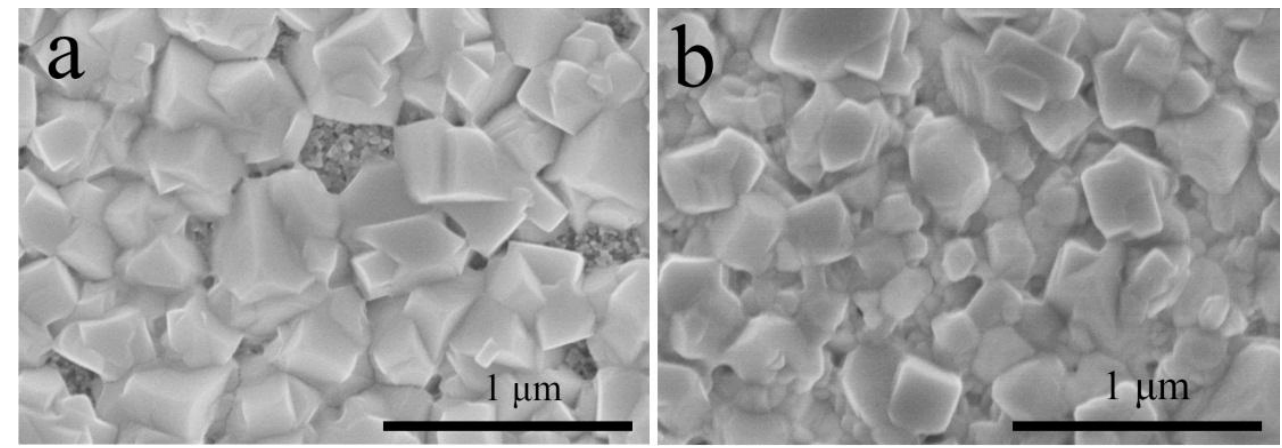

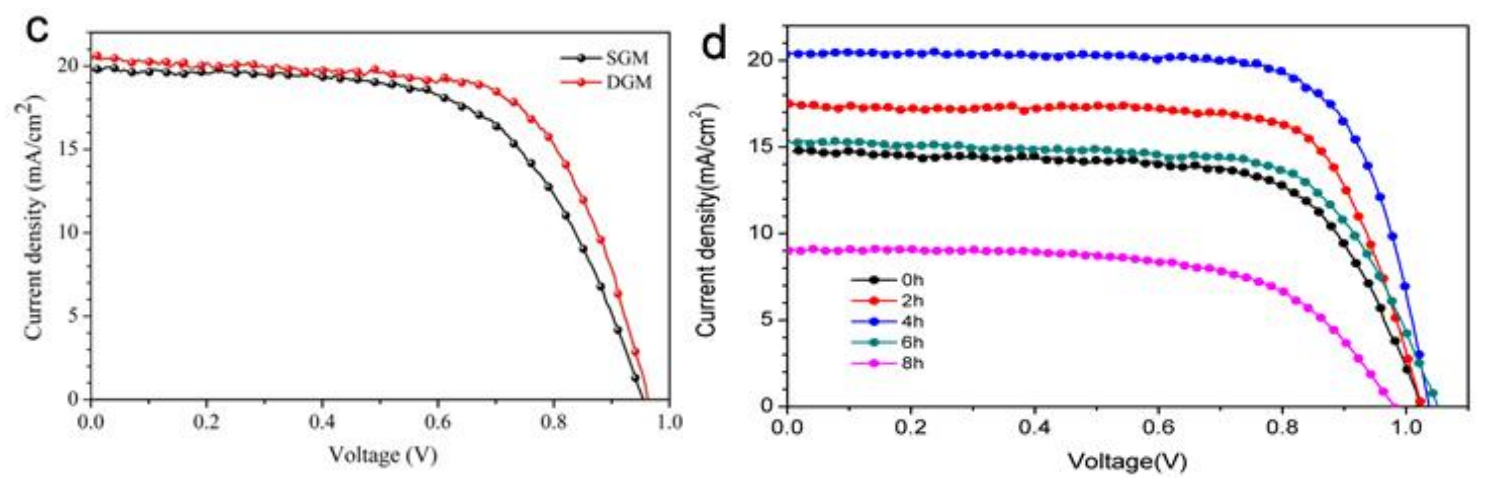

Figure 22. SEM images of perovskites prepared by (a) static growth process and (b) dynamic growth process, and (c) J-V curves of PSCs and (d) PSCs assembled $\mathrm{TiO}_{2}$ compact layers prepared by Sol-Gel using different aging time. (a-c) Reprinted from reference [145], (d) reprinted from reference [146].

The perovskites are usually deposited on a substrate by low temperature solution process, including one-step and two-step coating methods. Perovskite forms either by spin-coating a mixed $\mathrm{CH}_{3} \mathrm{NH}_{3} \mathrm{I}$ and $\mathrm{PbI}_{2}$ solution (one-step coating) or by spin coating $\mathrm{CH}_{3} \mathrm{NH}_{3} \mathrm{I}$ after coating with $\mathrm{PbI}_{2}$ (two-step coating). However, the two methods face a problem that is a poor stability of PCE, even under the same fabrication process parameters [144, 145]. One important reason should be attributed to the inhomogeneous perovskite film that fabricated by those methods. Controlling the morphology of perovskite crystallites have been regarded as an essential condition to guarantee reproducibility for high performance PSC [146-149]. Recently, a dynamic growth process was used to fabricate pervoskite crystallites. As shown in Figure 22 (a,b), the coverage rate of perovskites by this method is more than that of perovskites prepared by usual solution process. So the bareness of mesoporous $\mathrm{TiO}_{2}$ layer is significantly avoided [150]. Due to high quality perovskite capping layer, thePCE of the solar cell is increased from $11 \%$ to $13 \%$.

From the structure of PSCs, the compact MOS layer (such as c- $\mathrm{TiO}_{2}$ as shown in Figure 21) that plays an important role in charge transfer, which reduces the energy barrier between FTO and perovskites to increase the charge collection. As n-type semiconductor, the compact layer can transport the electrons and prevent the transfer of the holes. So it reduces the charge recombination at the interface of FTO and perovskite. Recently, some methods, such as ALD, magnetron sputtering, thermal spraying and sol-gel, have been used in the fabrication of the compact MOS layer[45, 61, 62, 143]. Among these methods, the sol-gel method is one of the most widely used methods due to flexible adjustability and low cost without complex equipment. For sol-gel process, the aging time and temperature are two key factors for the compact layer. In our recent work, the PCS with greater than 15\% of PCE was obtained by controlling the sol-gel aging of $\mathrm{TiO}_{2}$ compact layer as shown in Figure 22 (d) [151]. It 
was found that the sol-gel aging time is $4 \mathrm{~h}$ under room temperature, PCS shows the best performance: the highest and average values of PCEs are $15.6 \%$ and $14.01 \%$, respectively.

Most recently, scanning Kelvin probe force microscopy (SKPM) and photoconductive atomic force microscopy (pcAFM), were used in the investigation of the variation of the surface potential, photo-generated voltage, and photocurrent networks of the PSCs with different film topography [152]. Three perovskite $\mathrm{CH}_{3} \mathrm{NH}_{3} \mathrm{PbI}_{3}$ films with different morphologies and crystallite sizes as well as the corresponding complete PSC devices based on those three films were prepared as shown in Figure 23 [152]. It has been found that the defect regions on the capping layer showed little photovoltaic response while exhibited good conductivity, which can establish form small current paths for the photo-charge recombination. Accordingly, even though the P52 film with largest grain size shows most significant photovoltaic response in the KPFM measurement, the $\mathrm{V}_{\text {oc }}$ of P52-based PSCs was suppressed due to the existence of defect regions. Meanwhile, the insufficient exciton generation in the grain boundary region was also observed by the pcAFM measurement. Hence, P15 film with the smallest grain size can eliminate the defect region, while it can also reduce the $\mathrm{I}_{\mathrm{sc}}$ due to the increase of the grain boundary region.
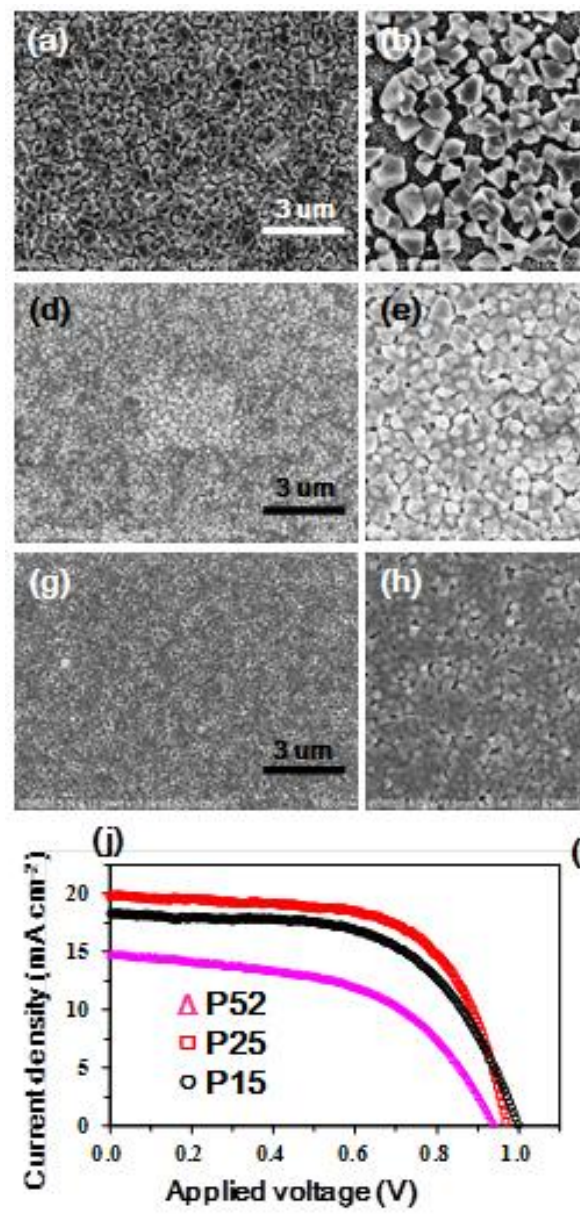

\section{(c)}
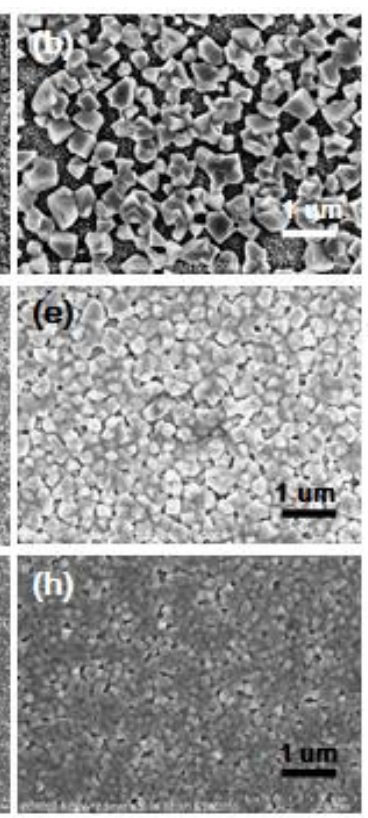

(k)

\begin{tabular}{lllll}
\hline Films & $\begin{array}{l}\text { Jsc } \\
\left(\mathbf{m A} \mathbf{c m}^{2}\right)\end{array}$ & $\begin{array}{l}\text { Voc } \\
(\mathbf{m V})\end{array}$ & $\begin{array}{l}\text { FF } \\
(\%)\end{array}$ & $\begin{array}{l}\text { PCE } \\
\mathbf{( \% )}\end{array}$ \\
\hline P52 & 14.8 & 0.94 & 53 & $7.4 \%$ \\
P25 & 19.8 & 0.98 & 63 & $12.3 \%$ \\
P15 & 18.3 & 1.00 & 59 & $10.9 \%$ \\
\hline
\end{tabular}


Figure 23. Three of perovskite-based films with different roughness and coverage rate have been studied in this experiment. The low (a, d, g) and large (b, e, h) magnified SEM images of the film surfaces and their corresponding three-dimensionally SPM images(c, f, i). The roughness were 52, 25, and $15 \mathrm{~nm}$ for (a-c), (d-f), and (g-h) films, respectively. For clarification, they are noted as P52, P25, and P15. (j) I-V curves measured for the perovskite solar cells employing these P52, P25, and P15 films from $0 \mathrm{~V}$ to $1 \mathrm{~V}$ bias voltage with $200 \mathrm{~ms}$ speed rate under AM $1.5 \mathrm{G}$ one sun $\left(100 \mathrm{~mW} / \mathrm{cm}^{2}\right)$. (i) Photovoltaic parameters obtained from $I$ - $V$ curves. Reprinted from reference [147].

\section{Inverted organic photovoltaic (OPVs)}

a)

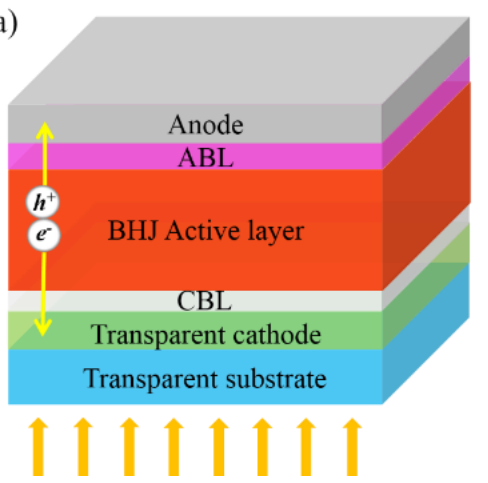

b)

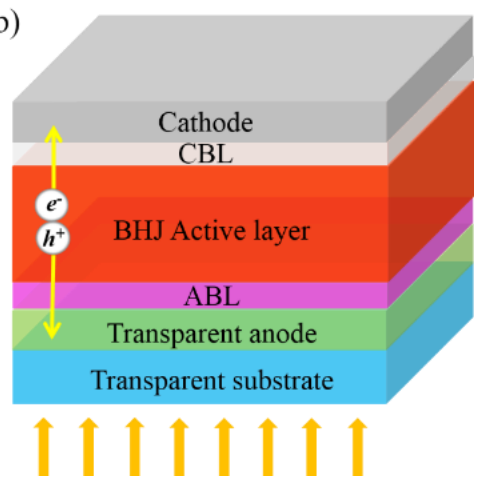

Figure 24. Schematic illustration of device structures of (a) inverted and (b) conventional OPVs with bulk heterojunction active layer. Reprinted from reference [13].

Figure 24(a) shows a schematic of an inverted OPV with a stacked structure of a transparent electrode (e.g., ITO, FTO and AZO), an interfacial layer named as cathode buffer layer (CBL), a BHJ active layer, an anode buffer layer (ABL) usually made of PEDOT:PSS, and a metal electrode with high-work-function such as Ag and Au [13]. The structure of conventional PSCs is also schematically presented in Figure 24(b) for comparison. In the inverted device architecture, the contact between the ITO and PEDOT:PSS is avoided, and meanwhile Al for top electrode adopted in conventional PSCs is replaced with an air stable high-work-function metal, such as $\mathrm{Au}$ or $\mathrm{Ag}[153,154]$. As a result, the inverted PSCs exhibit greatly improved ambient stability as compared to the PSCs with a conventional structure, overcoming one big hurdle for possible widespread application of PSCs [155-160]. The MOS used in the inverted OPVs deposited on ITO glass substrate serves as a CBL and is a critically important 
component. Its composition, morphology, structure, and crystallinity can largely affect the solar cell performance.

\subsection{Nanostructured TiO2 CBLs for OPVs}

\subsubsection{TiO2 mesoporous film}
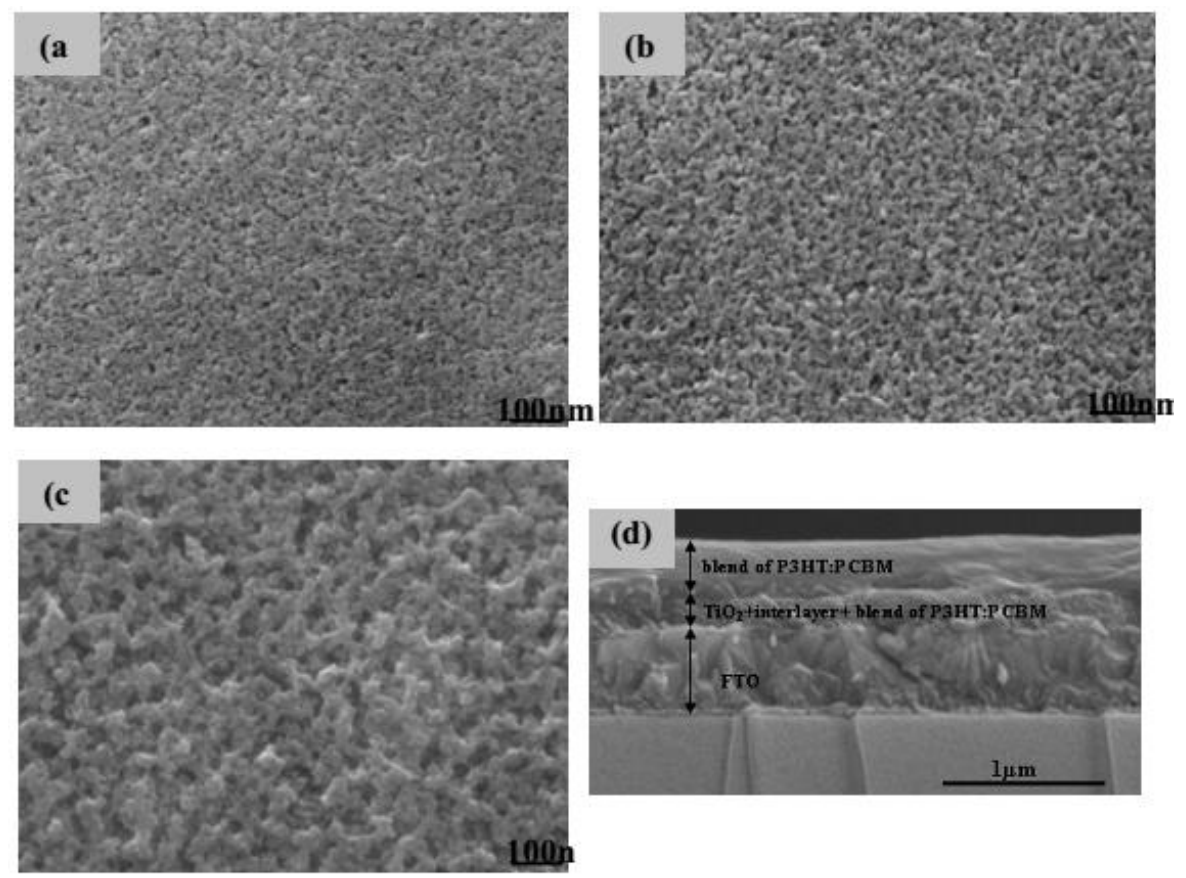

Figure 25. Top-view SEM images of (a) dense $\mathrm{TiO}_{2}$, (b) mesoporous $\mathrm{TiO}_{2}$ and (c) macroporousTiO $\mathrm{T}_{2}$ films, respectively; (d) The cross section SEM of an OPV using a porous $\mathrm{TiO}_{2}$ films. Reprinted from reference [153].

Besides facilitating the PCBM to form a continuous layer, CBL may play a role in enhancing the solar cell performance. We [161] found that, in the case of $\mathrm{a} \mathrm{TiO}_{2}$ mesoporous oxide film with the pore size of $\sim 10-20 \mathrm{~nm}$ as cathode buffer layer, the PCE of the OPV could reach a value as high as $3.4 \%$, while they were $1.7 \%$ and $1.9 \%$ when using a macroporous film with the size of 2-50 $\mathrm{nm}$ and a dense film, respectively. Figure 25 shows SEM images of dense, mesoporous and macroporous $\mathrm{TiO}_{2} \mathrm{CBLs}[161]$. When the conduction band bottom of the oxide such as $\mathrm{TiO}_{2}$ is lower than the LUMO level of PCBM and meanwhile the film thickness is not much larger than the electron diffusion length, the electron can transport within the oxide film efficiently, and the transport is much more efficient than within a polymer such as PCBM. When the CBL has a suitable structure, for example in this work it is a mesoporous film, the polymers can penetrate into the mesoporous film, leading to the formation a much large interface between the polymers and the oxide. This makes the electrons in the PCBM have a significantly increased probability to transport into the oxide before they get trapped during transport within the PCBM. Since the electron transport in an oxide is much more efficient than in a polymer, the use of nanostructure 
which stretches into the polymers to extract electrons can largely enhance the electron collection efficiency, resulting in the high efficiency. However, in the case of macroporous film, which was prepared by spin-coating a precursor solution which contains a sol of $\mathrm{TiO}_{2}$ and $\mathrm{PVP}$ additive stirred for a longer time (60 min) compared to the time $(30 \mathrm{~min})$ for the preparation of a mesoporous film, the nanocrystallites agglomerate to larger aggregates than in the mesoporous film, and the electron transport in the oxide becomes less efficient resulting from the size of aggregates larger than the diffusion length of electrons within the corresponding oxide. Consequently, the macroporous film achieved a PCE of $1.7 \%$, much lower than the $3.4 \%$ efficiency achieved by using a mesoporous film. This work illustrates that there is a trade-off between the nanostructure forming a large interface with the polymers to improve electron collection and it hindering electron transport in case of its size much larger than the electron diffusion length.

\subsubsection{TiO2 nanorod array}

(a)

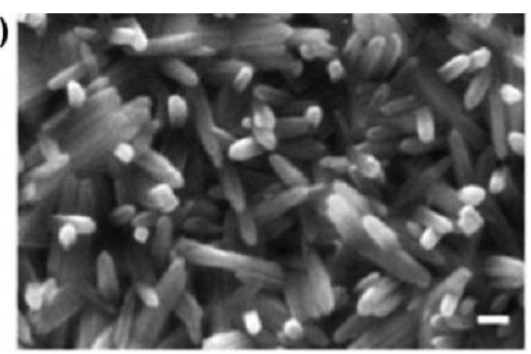

(c)

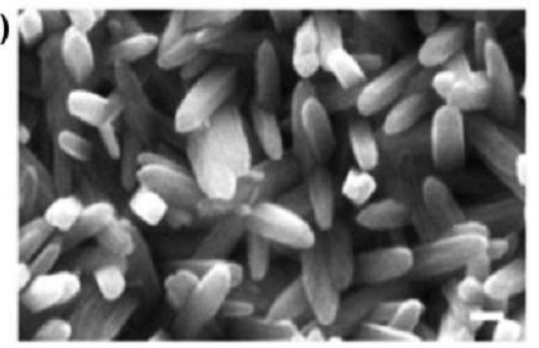

(e)

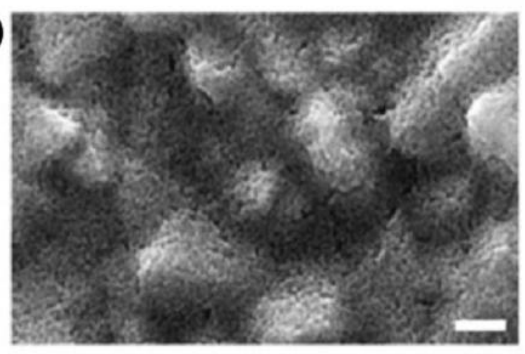

(b)

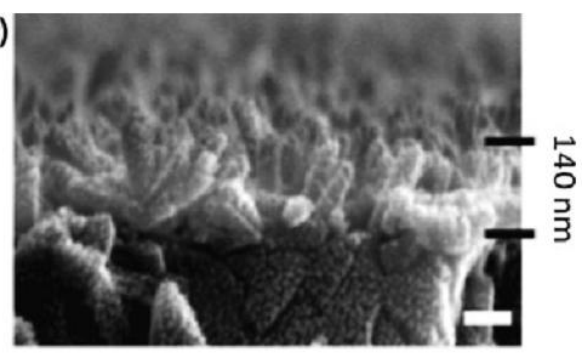

(d)

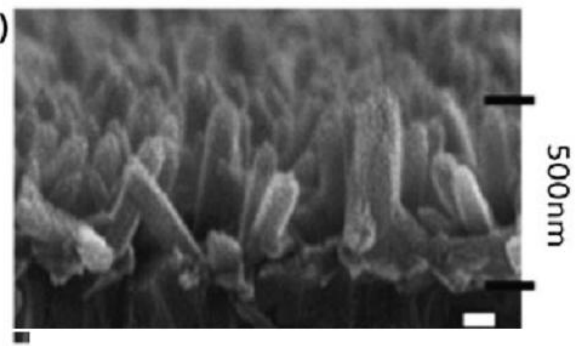

(f)

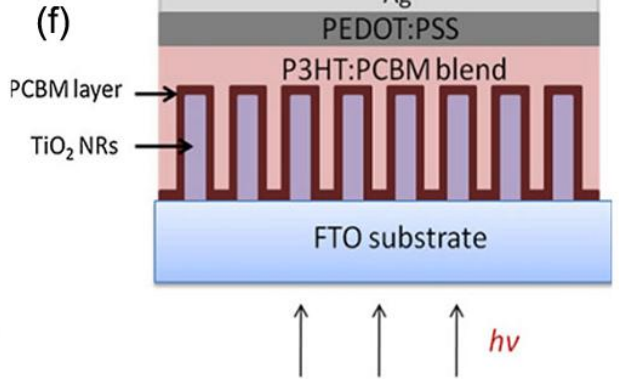

Figure 26. The top-view and cross section SEM images of $\mathrm{TiO}_{2}$ nanorods with length of $140 \mathrm{~nm}(\mathrm{a}, \mathrm{b})$, and nanorod with length of $500 \mathrm{~nm}$ (c, d). (e) SEM image of $\mathrm{TiO}_{2}$ dense film. The scale bars are all $100 \mathrm{~nm}$. (f) Schematic of the OPV based on $\mathrm{TiO}_{2}$ naorods array CBL. Reprinted from reference [154]. 
Nanostructured $\mathrm{TiO}_{2}$ for the enhancement of electron collection in OPVs have also demonstrated in another work with regard to the use of $\mathrm{TiO}_{2}$ nanorod array grown on a FTO glass substrate through a hydrothermal method as shown Figure 26 [162]. By controlling the time for hydrothermal growth, the length of nanorods (i.e., the height of the nanorod array) could be adjusted. When the nanorod arrays were used as the CBL in OPVs, it was observed that the solar cell efficiency could be much affected by the length of nanorods. For the nanorods $\sim 150$ $\mathrm{nm}$ in length, the solar cell reached a high PCE of $\sim 3.21 \%$, which was apparently higher than the efficiency of $2.70 \%$ when using the nanorods with a length of $\sim 500 \mathrm{~nm}$, and was also higher than the efficiency of $2.79 \%$ when using a very thin $\mathrm{TiO}_{2}$ dense film. The high efficiency obtained for the solar cell using the nanorods with a relatively small length was explained that, similar to the mechanism in the case of mesoporous film mentioned above, the nanorods stretching into the polymers resulted in a large oxide/polymer interface and could thus improve the electron transport and collection. However, when the nanorods were as long as $500 \mathrm{~nm}$ (which is much larger than the electron diffusion length in $\mathrm{TiO}_{2}$ ), although the $\mathrm{TiO}_{2}$ nanorods were single crystalline, the electron transport through the entire nanorods became somewhat difficult, leading to electron traps to a large extent and thus giving rise to a smaller photocurrent density than in the case of short nanorods $\left(9.05 \mathrm{~mA} / \mathrm{cm}^{2}\right.$ for $500 \mathrm{~nm}$ and $10.06 \mathrm{~mA} / \mathrm{cm}^{2}$ for $150 \mathrm{~nm}$ ). This eventually yielded a low PCE. It had also been observed that the solar cell with the long nanorods presented a fill factor (FF), 51.3\%, lower than the fill factor of 53.6\% for short nanorods and $53.8 \%$ for dense film. This can be explained that, in the case of too long nanorods, the polymers is hard to penetrate into the entire nanorod array so that the bottom area of the nanorod array is not fully covered by the polymers, resulting in an increase in the series resistance of the solar cell.

\subsection{Nanostructured ZnO CBLs for OPVs}

\subsubsection{ZnO dense layer}

$\mathrm{ZnO}$ has drawn much attention in serve as the buffer layer because it has good transparency across the whole visible spectral range, relatively high electron mobility, and environmental stability [13, 163]. Recently, we compared the efficiencies of OPVs constructed with $\mathrm{ZnO}$ dense CBL having different thickness and roughness achieved by changing the concentration of the $\mathrm{ZnO}$ sol used for the fabrication of cathode buffer layer [163]. It was revealed that, when the thickness of $\mathrm{ZnO}$ film varied from $20 \mathrm{~nm}$ to $65 \mathrm{~nm}$, the PCE basically remained the same, around $3.1 \%$. In other words, the solar cell efficiency is not sensitive to the thickness of the CBL. This makes sense considering that the film thicknesses in 20-65 $\mathrm{nm}$ are comparable to the electron diffusion length in $\mathrm{ZnO}$ and, therefore, the electron transport within the CBL is not affected perceptibly by varying the film thickness. 
However, it was found that the solar cell efficiency could be significantly affected by the roughness of the cathode buffer layer; a smaller roughness gave rise to higher power conversion efficiency, which increased from $1.82 \%$ to $3.30 \%$ when the roughness (as shown in Figure 27 measured with AFM) decreased from $4.25 \mathrm{~nm}$ to $2.86 \mathrm{~nm}$. It was explained that the $\mathrm{ZnO}$ cathode buffer layer with small roughness could lead to a good contact with the polymer, which benefited the electron transport at the polymer/ZnO interface and meanwhile gave rise to the solar cell with low series resistance; in the case of large roughness, there likely formed some voids at the polymer/ZnO interface, which hindered the electron transport and increased the series resistance of the solar cell. Such a speculated mechanism was in line with the experimental observation that higher photocurrent density and larger fill factor were obtained in the case of smaller roughness.
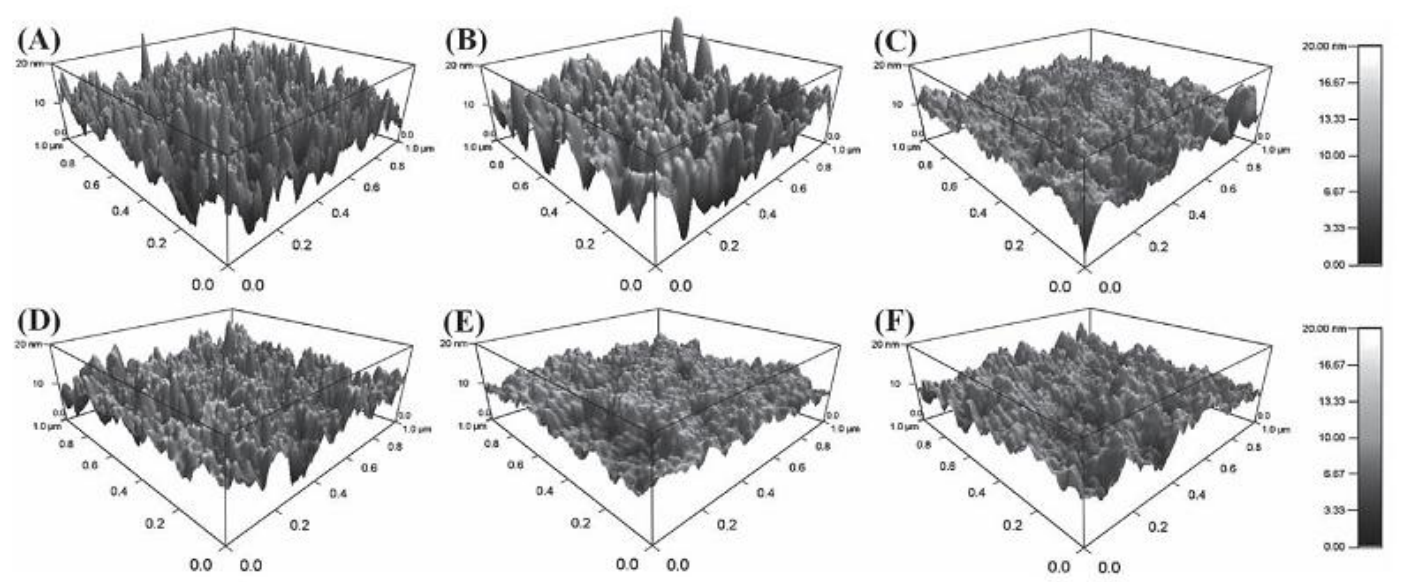

Figure 27. 3D AFM images of the $\mathrm{ZnO}$ buffer layers of devices $\mathrm{A}, \mathrm{B}, \mathrm{C}, \mathrm{D}, \mathrm{E}$, and F, which were deposited by spin-coating $0.02,0.05,0.1,0.3,0.6$, and $1 \mathrm{M}$ sol one time. Reprinted from reference [155].

\subsection{2 $\mathrm{SrTiO}_{3}: \mathrm{ZnO}$ composite layer}

Compared with $\mathrm{ZnO}, \mathrm{SrTiO}_{3}$ has a higher dielectric constant $\left(\sim 10^{4}\right)$, similar band gap structure, but lower electron mobility. It was hypothesized that the material with larger dielectric constant and spontaneous polarization, such as $\mathrm{SrTiO}_{3}$, may create an internal electric field while PSCs operation. Such a high dielectric constant material would favor the effective charge transfer in OPVs. $\mathrm{SrTiO}_{3}: \mathrm{ZnO} \mathrm{CBL}$ was used in OPVs as shown in Figure $28(a, b)$ [164]. The fabrication of $\mathrm{SrTiO}_{3}: \mathrm{ZnO} \mathrm{CBL}$ was achieved by mixing a sol of $\mathrm{SrTiO}_{3}$ and a sol of $\mathrm{ZnO}$ in certain molar ratios and then spin coating on a ITO glass substrate followed by a heat treatment at $350{ }^{\circ} \mathrm{C}$ to enable the formation of $\mathrm{SrTiO}_{3}: \mathrm{ZnO}$ composite. The ratios of $\mathrm{SrTiO}_{3}$ to $\mathrm{ZnO}$ changed from 5:95, 10:90, $15: 85,20: 80$, to $25: 75$. It was revealed that the solar cell efficiency increased from $3.58 \%$ for pure $\mathrm{ZnO}$ to $4.10 \%$ for the ratio of $\mathrm{SrTiO}_{3}: \mathrm{ZnO}$ being 10:90; a further increase of the $\mathrm{SrTiO}_{3}: \mathrm{ZnO}$ ratio however led to a decrease in 
the efficiency, which dropped to 2.38\% when the ratio was 25:75 as shown in Figure 30 (c). The increase in the solar cell efficiency was found to result from an increase in the FF of the solar cell while the open-circuit voltage and short-circuit photocurrent density didn't show an apparent change. The increase in the FF likely suggests that the contact between the polymers and the $\mathrm{CBL}$ is improved in view of the addition of suitable amount of $\mathrm{SrTiO}_{3}$ to $\mathrm{ZnO}$, which changes the surface status of $\mathrm{ZnO}$ (possibly due to local spontaneous polarization of the $\mathrm{SrTiO}_{3}$ ) and results in the interface between the polymers and cathode buffer layer with a relatively low energy barrier; a low energy barrier is beneficial to the electron transport over the polymer/CBL interface especially when the kinetic energy of electrons is small, corresponding to the high voltage range (adjacent to open-circuit voltage) during the $\mathrm{I}-\mathrm{V}$ measurement. The allowing of the electrons with small kinetic energy to transport through the polymer/CBL interface straightforwardly leads to an increase in the FF.
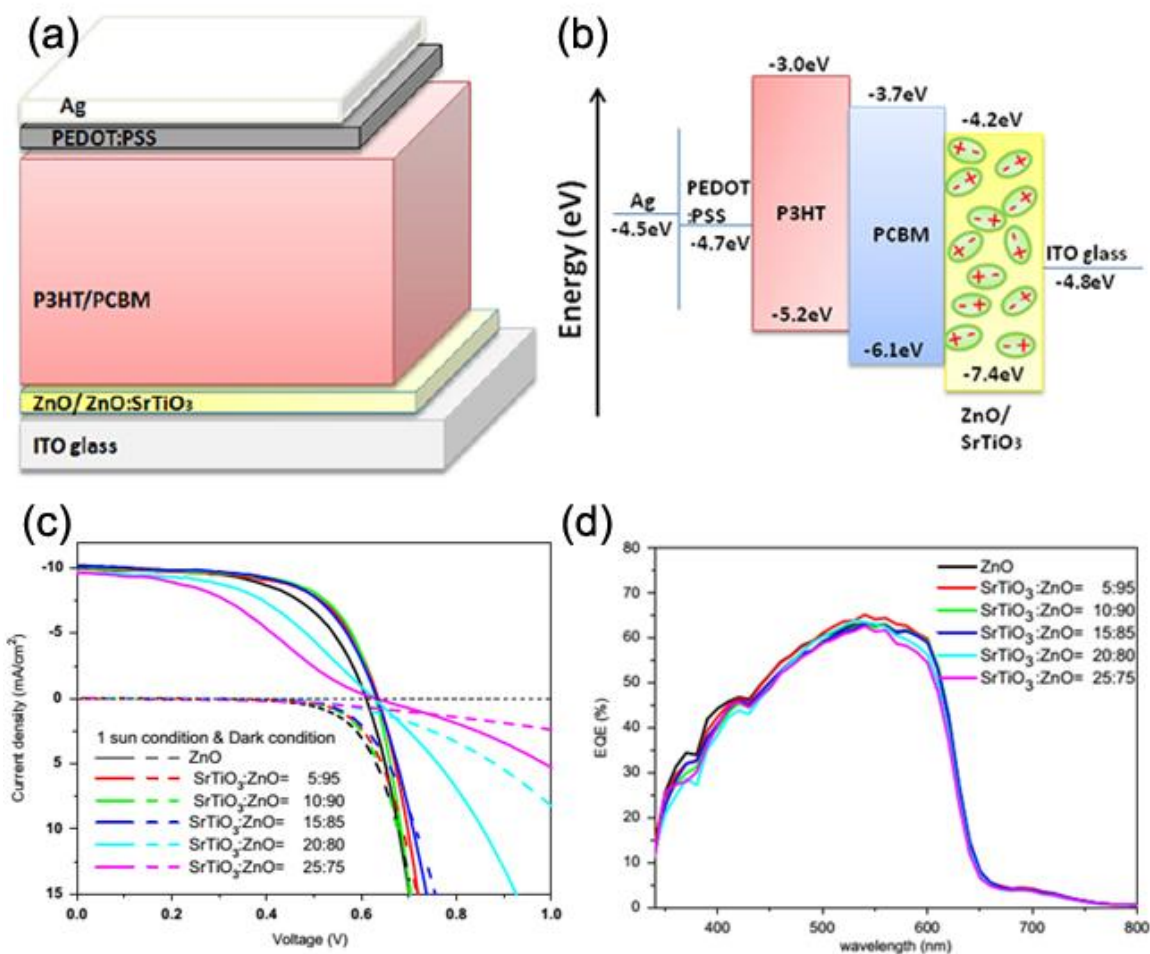

Figure 28. (a, b) OPVs and the corresponding energy level diagram of the components of the devices, (c) I-V curve at 1 sun and dark condition with various $\mathrm{SrTiO}_{3}: \mathrm{ZnO}$ films as the cathodic buffer layer and (d) IPCE results of various $\mathrm{SrTiO}_{3}: \mathrm{ZnO}$ films as CBLs. Reprinted from reference [156].

\subsection{3 $\mathrm{Ta}_{2} \mathrm{O}_{5}: \mathrm{ZnO}$ composite layer}

Similar to $\mathrm{SrTiO}_{3}, \mathrm{Ta}_{2} \mathrm{O}_{5}$ is also known for its high dielectric constant and index of refraction, which is helpful for the effective charge transfer in OPVs. $\mathrm{Ta}_{2} \mathrm{O}_{5}: \mathrm{ZnO}$ is another composite studied for CBL of OPVs [165]. The results are very similar to what are obtained for $\mathrm{SrTiO}_{3}: \mathrm{ZnO}$ as shown in Table 3. It was observed that the 
PCE of OPV increased gradually when the percentage of $\mathrm{Ta}_{2} \mathrm{O}_{5}$ in the composite increased from 0 to $18 \%$ (in molar), and when the percentage is higher than $18 \%$, the efficiency dropped quickly. For pure $\mathrm{ZnO}$ (i.e., $0 \%$ $\mathrm{Ta}_{2} \mathrm{O}_{5}$ ), the PCE was $3.70 \%$. The maximum efficiency corresponding to $18 \% \mathrm{Ta}_{2} \mathrm{O}_{5}$ was $4.12 \%$. When $\operatorname{Ta}_{2} \mathrm{O}_{5}$ was $30 \%$, the efficiency was as low as $1.26 \%$. When the $\mathrm{CBL}$ only consisted of $\mathrm{Ta}_{2} \mathrm{O}_{5}$, the solar cell efficiency was nearly close to zero. Same as the case of $\mathrm{SrTiO}_{3}: \mathrm{ZnO}$, when the content of $\mathrm{Ta}_{2} \mathrm{O}_{5}$ increased from 0 to $18 \%$, the increase in PCE mainly resulted from an increase in FF, from 0.61 for pure $\mathrm{ZnO}$ to 0.67 for $18 \% \mathrm{Ta}_{2} \mathrm{O}_{5}$, while the solar cell's open-circuit voltage and short-circuit current density didn't show an apparent change. When the content of $\mathrm{Ta}_{2} \mathrm{O}_{5}$ exceeded $18 \%$, it was found that the electron mobility of the $\mathrm{SrTiO}_{3}: \mathrm{ZnO}$ films decreased greatly with increasing the amount of $\mathrm{Ta}_{2} \mathrm{O}_{5}$ in the composite, and as a result the series resistance of the solar cell increased significantly, which were $7.28 \Omega \mathrm{cm}^{2}$ for $18 \% \mathrm{Ta}_{2} \mathrm{O}_{5}, 10.07 \Omega \mathrm{cm}^{2}$ for $24 \% \mathrm{Ta}_{2} \mathrm{O}_{5}$, and $243.9 \Omega \mathrm{cm}^{2}$ for $30 \%$ $\mathrm{Ta}_{2} \mathrm{O}_{5}$. The mechanism of $\mathrm{Ta}_{2} \mathrm{O}_{5}: \mathrm{ZnO}$ composite CBL enhancing the solar cell efficiency is same as what was depicted above for $\mathrm{SrTiO}_{3}: \mathrm{ZnO}$. The addition of $\mathrm{Ta}_{2} \mathrm{O}_{5}$ to $\mathrm{ZnO}$ gives the cathode buffer layer with a surface status different from that of $\mathrm{ZnO}$ film. When the amount of $\mathrm{Ta}_{2} \mathrm{O}_{5}$ is suitable, it seems that the use of $\mathrm{Ta}_{2} \mathrm{O}_{5}: \mathrm{ZnO}$ composite can improve the contact between the polymers and the cathode buffer layer, so as to enable the formation of an interface with low energy barrier, which benefits the solar cell with increasing its fill factor. However, when the composite contains too much $\mathrm{Ta}_{2} \mathrm{O}_{5}$, for example, over $18 \%$ as revealed by this work, a dramatic decrease in the electron mobility will largely increase the series resistance of the solar cell and result in a low efficiency. So the study of the use of composites for CBL of OPVs delivers new understanding to the criteria for choosing material for the CBL.

Table 3. Properties of OPVs with various $\mathrm{Ta}_{2} \mathrm{O}_{5}: \mathrm{ZnO}$ CBLs [165].

\begin{tabular}{ccccccc}
\hline $\mathrm{Ta}_{2} \mathrm{O}_{5} / \%$ & $\mathrm{~V}_{\mathrm{oc}} / \mathrm{V}$ & $\mathrm{J}_{\mathrm{sc}} / \mathrm{mA} \mathrm{cm}^{-2}$ & $\mathrm{FF}$ & $\mathrm{PCE} / \%$ & $\mathrm{R}_{\mathrm{sh}} / \mathrm{k} \Omega \mathrm{cm}^{2}$ & $\mathrm{R}_{\mathrm{s}} / \mathrm{k} \Omega \mathrm{cm}^{2}$ \\
\hline 0 & 0.636 & 9.49 & 0.613 & 3.70 & 0.67 & 8.72 \\
6 & 0.637 & 9.75 & 0.649 & 4.03 & 1 & 7.58 \\
12 & 0.634 & 9.73 & 0.661 & 4.08 & 5 & 7.20 \\
18 & 0.637 & 9.64 & 0.670 & 4.12 & 3.3 & 7.28 \\
24 & 0.631 & 9.75 & 0.616 & 3.79 & 1.67 & 10.07 \\
30 & 0.563 & 8.61 & 0.260 & 1.26 & 0.2 & 243.9 \\
100 & 0.564 & 0.04 & 0.374 & 0.0009 & 11 & 125000 \\
\hline
\end{tabular}

As it was mentioned in the beginning of section 5, one of the biggest attraction of inverted OPVs is its 
excellent ambient stability in comparison with the conventional OPVs. The PCE of the unencapsulated inverted organic photovoltaics was periodically measured for 42 days to monitor their long-term stability in air (Figure 29). All devices retained around $100 \%$ of the magnitude of their original power conversion efficiency after being exposed to ambient conditions for 42 days. This explicitly demonstrates the superior air stability of inverted organic photovoltaics.

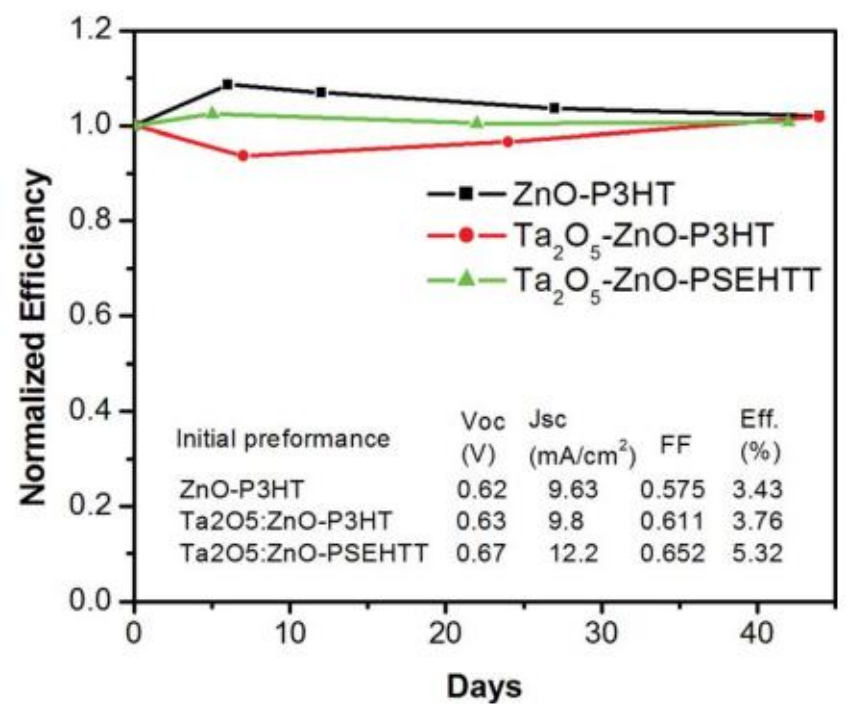

Figure 29. The long term stability of inverted OPVs with $\mathrm{ZnO}$ or $\mathrm{Ta}_{2} \mathrm{O}_{5}: \mathrm{ZnO}$ films as $\mathrm{CBL}$; the devices were stored in ambient conditions. Reprinted from reference [160].

\section{Concluding remarks}

As the essential component, MOSs, such as $\mathrm{TiO}_{2}, \mathrm{ZnO}$ and $\mathrm{SnO}_{2}$ have been widely used in the ESCs including DSCs, QDSCs, PSCs and OPVs. With the development of nanotechnology, a big breakthrough in ESCs will be made due to the novel nano-architectures of MOSs. For example, hierarchical nanostructured MOSs not only offer large specific surface area for loading a large amount of active materials (dyes, quantum dots or perovskites), but also have strong light scattering to capture a sufficient fraction of photons. This review summarized the recent works on the structure design, fabrication, and surface modification of MOSs to enhance PCE of ESCs. In addition to the design and fabrication of the nanostructured MOSs, it was also found that the poor chemical stability and lots of surface defects of nanostructured MOSs caused much high surface charge recombination of the solar cells, which resulted in the decrease of PCE. So the rational design and engineering surface and interface chemistry would favor charge transfer and at the same time prevent or minimize the charge recombination of the solar cells. 


\section{Acknowledgments}

This work was supported by the National Science Foundation of China $(51374029,5151101345)$ and by the National Science Foundation (NSF, DMR-1505902), Program for New Century Excellent Talents in University (NCET-13-0668), Fundamental Research Funds for the Central Universities (FRF-TP-14-008C1). This work was also supported by the "thousands talents" program for pioneer researcher and his innovation team, China.

\section{References}

[1] E.J.W. Crossland, N. Noel, V. Sivaram, T. Leijtens, J.A. Alexander-Webber, H.J. Snaith, Nature 495 (2013) 215.

[2] J.S. Chen, Y.L. Tan, C.M. Li, Y.L. Cheah, D.Y. Luan, S. Madhavi, F.Y.C. Boey, L.A. Archer, X.W. Lou, J. Am. Chem. Soc. 132 (2010) 6124.

[3] Y. Izumi, Coord. Chem. Rev. 257 (2013) 171.

[4] L. Mai, X. Tian, X. Xu, L. Chang, L. Xu, Chem. Rev. 114 (2014) 11828.

[5] J. Schneider, M. Matsuoka, M. Takeuchi, J. Zhang, Y. Horiuchi, M. Anpo, D.W. Bahnemann, Chem. Rev. 114 (2014) 9919.

[6] L. Jing, W. Zhou, G. Tian, H. Fu, Chem. Soc. Rev. 42 (2013) 9509.

[7] H. Zeng, G. Duan, Y. Li, S. Yang, X. Xu, W. Cai, Adv. Funct. Mater. 20 (2010) 561.

[8] Q. Zhang, E. Uchaker, S.L. Candelaria, G. Cao, Chem. Soc. Rev. 42 (2013) 3127.

[9] E. Uchaker, G. Cao, Nano Today 9 (2014) 499.

[10] R.C. Massé, E. Uchaker, G. Cao, Sci. China Mater. 58 (2015) 715.

[11] I. Concina, A. Vomiero, Small 11 (2015) 1744.

[12] Q.F. Zhang, G.Z. Cao, Nano Today 6 (2011) 91.

[13] Z. Liang, Q. Zhang, L. Jiang, G. Cao, Energy Environ. Sci. 8 (2015) 3442.

[14] M. Graetzel, R.A.J. Janssen, D.B. Mitzi, E.H. Sargent, Nature 488 (2012) 304.

[15] T. Kinoshita, J.T. Dy, S. Uchida, T. Kubo, H. Segawa, Nat. Photonics 7 (2013) 535.

[16] H. Tada, M. Fujishima, H. Kobayashi, Chem. Soc. Rev. 40 (2011) 4232.

[17] G. Li, V. Shrotriya, J. Huang, Y. Yao, T. Moriarty, K. Emery, Y. Yang, Nat. Mater. 4 (2005) 864.

[18] S.K. Hau, H.-L. Yip, A.K.Y. Jen, Polym. Rev. 50 (2010) 474.

[19] R. Po, C. Carbonera, A. Bernardi, N. Camaioni, Energy \& Environmental Science, 4 (2011) 285-310.

[20] G. Li, R. Zhu, Y. Yang, Nat. Photonics 6 (2012) 153.

[21] F. He, L. Yu, The Journal of Physical Chemistry Letters, 2 (2011) 3102-3113.

[22] B. Oregan, M. Gratzel, Nature, 353 (1991) 737-740.

[23] I. Robel, V. Subramanian, M. Kuno, P.V. Kamat, J. Am. Chem. Soc. 128 (2006) 2385.

[24] Q.F. Zhang, G.Z. Cao, J. Mater. Chem. 21 (2011) 6769.

[25] T. Bessho, E. Yoneda, J.H. Yum, M. Guglielmi, I. Tavernelli, H. Imai, U. Rothlisberger, M.K. Nazeeruddin, M. Gratzel, J. Am. Chem. Soc. 131 (2009) 5930.

[26] P.G. Bomben, K.C.D. Robson, P.A. Sedach, C.P. Berlinguette, Inorganic Chemistry, 48 (2009) 9631-9643.

[27] P.G. Johansson, J.G. Rowley, A. Taheri, G.J. Meyer, Langmuir 27 (2011) 14522.

[28] H.C. Zhao, J.P. Harney, Y.T. Huang, J.H. Yum, M.K. Nazeeruddin, M. Gratzel, M.K. Tsai, J. Rochford, Inorg. 
Chem. 51 (2012) 1.

[29] S. Mathew, A. Yella, P. Gao, R. Humphry-Baker, B.F.E. Curchod, N. Ashari-Astani, I. Tavernelli, U. Rothlisberger, M.K. Nazeeruddin, M. Graetzel, Nat. Chem. 6 (2014) 242.

[30] J. Kim, H. Choi, C. Nahm, J. Moon, C. Kim, S. Nam, D.-R. Jung, B. Park, J. Power Sources 196 (2011) 10526.

[31] S. Panigrahi, D. Basak, J. Colloid Interf. Sci. 364 (2011) 10.

[32] Q. Shen, J. Kobayashi, L.J. Diguna, T. Toyoda, J.Appl. Phys. 103 (2008) 084304.

[33] R. Plass, S. Pelet, J. Krueger, M. Gratzel, U. Bach, J. Phys. Chem. B 106 (2002) 7578.

[34] P. Yu, K. Zhu, A.G. Norman, S. Ferrere, A.J. Frank, A.J. Nozik, J. Phys. Chem. B 110 (2006) 25451.

[35] G. Zhu, L. Pan, T. Xu, Z. Sun, ACS Appl. Mater. Interfaces 3 (2011) 3146.

[36] Y.L. Lee, Y.S. Lo, Adv. Funct. Mater. 19 (2009) 604.

[37] J.J. Tian, R. Gao, Q.F. Zhang, S.G. Zhang, Y.W. Li, J.L. Lan, X.H. Qu, G.Z. Cao, J. Phys. Chem. C 116 (2012) 18655 .

[38] J. Tian, L. Lv, C. Fei, Y. Wang, X. Liu, G. Cao, J. Mater. Chem. A 2 (2014) 19653.

[39] P.V. Kamat, J.A. Christians, J.G. Radich, Langmuir 30 (2014) 5716.

[40] Z. Pan, K. Zhao, J. Wang, H. Zhang, Y. Feng, X. Zhong, ACS Nano 7 (2013) 5215.

[41] J. Wang, I. Mora-Sero, Z. Pan, K. Zhao, H. Zhang, Y. Feng, G. Yang, X. Zhong, J. Bisquert, J. Am. Chem. Soc. 135 (2013) 15913.

[42] K. Zhao, Z. Pan, I. Mora-Sero, E. Canovas, H. Wang, Y. Song, X. Gong, J. Wang, M. Bonn, J. Bisquert, X. Zhong, J. Am. Chem. Soc. 137 (2015) 5602.

[43] D.A. Hines, P.V. Kamat, ACS Appl. Mater. Interfaces 6 (2014) 3041.

[44] A. Kojima, K. Teshima, Y. Shirai, T. Miyasaka, J. Am. Chem. Soc. 131 (2009) 6050.

[45] H.S. Jung, N.G. Park, Small 11 (2015) 10.

[46] J.-H. Im, C.-R. Lee, J.-W. Lee, S.-W. Park, N.-G. Park, Nanoscale 3 (2011) 4088.

[47] M.M. Lee, J. Teuscher, T. Miyasaka, T.N. Murakami, H.J. Snaith, Science 338 (2012) 643.

[48] W.S. Yang, J.H. Noh, N.J. Jeon, Y.C. Kim, S. Ryu, J. Seo, S.I. Seok, Science 348 (2015) 1234.

[49] Y.J. Cheng, S.H. Yang, C.S. Hsu, Chem. Rev. 109 (2009) 5868.

[50] K. Ramasamy, M.A. Malik, N. Revaprasadu, P. O’Brien, Chem. Mater. 25 (2013) 3551.

[51] A.J. Nozik, Nano Lett. 10 (2010) 2735.

[52] D. Koziej, A. Lauria, M. Niederberger, Adv. Mater. 26 (2014) 235.

[53] H. Wang, A.L. Rogach, Chem. Mater. 26 (2014) 123.

[54] Y. Bai, I. Mora-Sero, F. De Angelis, J. Bisquert, P. Wang, Chem. Rev. 114 (2014) 10095.

[55] Z. Chen, D. Pan, Z. Li, Z. Jiao, M. Wu, C.H. Shek, C.M. Wu, J.K. Lai, Chem. Rev. 114 (2014) 7442.

[56] J. Xu, Z.H. Chen, J.A. Zapien, C.S. Lee, W.J. Zhang, Adv. Mater. 26 (2014) 5337.

[57] A. Hagfeldt, G. Boschloo, L. Sun, L. Kloo, H. Pettersson, Chem. Rev. 110 (2010) 6595.

[58] M. Ye, X. Wen, M. Wang, J. Iocozzia, N. Zhang, C. Lin, Z. Lin, Mater. Today 18 (2015) 155.

[59] I. Mora-Sero, S. Gimenez, F. Fabregat-Santiago, R. Gomez, Q. Shen, T. Toyoda, J. Bisquert, Acc. Chem. Res. 42 (2009) 1848.

[60] S. Zhang, X. Yang, Y. Numata, L. Han, Energy Environ. Sci. 6 (2013) 1443.

[61] T.C. Sum, N. Mathews, Energy Environ. Sci. 7 (2014) 2518.

[62] P.P. Boix, K. Nonomura, N. Mathews, S.G. Mhaisalkar, Mater. Today 17 (2014) 16.

[63] Q. Zhang, D. Myers, J. Lan, S.A. Jenekhe, G. Cao, Phys. Chem. Chem. Phys. 14 (2012) 14982.

[64] J. Tian, G. Cao, J. Phys. Chem. Lett. 6 (2015) 1859.

[65] A. Hagfeldt, M. Gratzel, Acc. Chem. Res. 33 (2000) 269. 
[66] X. Feng, K. Zhu, A.J. Frank, C.A. Grimes, T.E. Mallouk, Angew. Chem. Int. Edit. 51 (2012) 2727.

[67] Y.J. Kim, M.H. Lee, H.J. Kim, G. Lim, Y.S. Choi, N.-G. Park, K. Kim, W.I. Lee, Adv. Mater. 21 (2009) 3668.

[68] J. Wang, Z. Lin, Chem. Mater. 20 (2008) 1257.

[69] M.D. Ye, X.K. Xin, C.J. Lin, Z.Q. Lin, Nano Lett. 11 (2011) 3214.

[70] J. Lin, Y.U. Heo, A. Nattestad, Z. Sun, L. Wang, J.H. Kim, S.X. Dou, Sci. Rep. 4 (2014) 5769.

[71] Y. Bai, H. Yu, Z. Li, R. Amal, G.Q. Lu, L. Wang, Adv. Mater. 24 (2012) 5850.

[72] Z. Dong, H. Ren, C.M. Hessel, J. Wang, R. Yu, Q. Jin, M. Yang, Z. Hu, Y. Chen, Z. Tang, H. Zhao, D. Wang, Adv. Mater. 26 (2014) 905.

[73] Y. Shi, K. Wang, Y. Du, H. Zhang, J. Gu, C. Zhu, L. Wang, W. Guo, A. Hagfeldt, N. Wang, T. Ma, Adv. Mater. 25 (2013) 4413.

[74] R. Gao, J. Tian, Z. Liang, Q. Zhang, L. Wang, G. Cao, Nanoscale 5 (2013) 1894.

[75] W. Wang, H. Zhang, R. Wang, M. Feng, Y. Chen, Nanoscale 6 (2014) 2390.

[76] R. Gao, Z. Liang, J. Tian, Q. Zhang, L. Wang, G. Cao, Nano Energy 2 (2013) 40.

[77] T.P. Chou, Q.F. Zhang, G.E. Fryxell, G.Z. Cao, Adv. Mater. 19 (2007) 2588.

[78] J. Xi, Q. Zhang, K. Park, Y. Sun, G. Cao, Electrochim. Acta 56 (2011) 1960.

[79] Q.F. Zhang, T.R. Chou, B. Russo, S.A. Jenekhe, G.Z. Cao, Angew. Chem. Int. Edit. 47 (2008) 2402.

[80] Q. Zhang, T.P. Chou, B. Russo, S.A. Jenekhe, G. Cao, Adv. Funct. Mater. 18 (2008) 1654.

[81] Q. Zhang, K. Park, J. Xi, D. Myers, G. Cao, Adv. Energy Mater. 1 (2011) 988.

[82] Q.F. Zhang, C.S. Dandeneau, X.Y. Zhou, G.Z. Cao, Adv. Mater. 21 (2009) 4087.

[83] M.J. Alam, D.C. Cameron, J. Sol-Gel Sci. Techn. 25 (2002) 137.

[84] K.-i. Katsumata, Y. Ohno, K. Tomita, T. Taniguchi, N. Matsushita, K. Okada, ACS Appl. Mater. Interfaces 4 (2012) 4846.

[85] C.-T. Dinh, T.-D. Nguyen, F. Kleitz, T.-O. Do, Acs Nano 3 (2009) 3737.

[86] T.R. Gordon, M. Cargnello, T. Paik, F. Mangolini, R.T. Weber, P. Fornasiero, C.B. Murray, J. Am. Chem. Soc. 134 (2012) 6751.

[87] I. Bilecka, M. Niederberger, Nanoscale 2 (2010) 1358.

[88] X. Wang, J. Tian, C. Fei, L. Lv, Y. Wang, G. Cao, RSC Adv. 5 (2014) 8622.

[89] K. Park, Q. Zhang, J. Xi, G. Cao, Thin Solid Films 588 (2015) 19.

[90] Z. Zhao, G. Liu, B. Li, L. Guo, C. Fei, Y. Wang, L. Lv, X. Liu, J. Tian, G. Cao, J. Mater. Chem. A 3 (2015) 11320 .

[91] Q.F. Zhang, S. Yodyingyong, J.T. Xi, D. Myers, G.Z. Cao, Nanoscale 4 (2012) 1436.

[92] M. Law, L.E. Greene, A. Radenovic, T. Kuykendall, J. Liphardt, P.D. Yang, J. Phys. Chem. B 110 (2006) 22652.

[93] S. Zhu, L. Shan, X. Chen, L. He, J. Chen, M. Jiang, X. Xie, Z. Zhou, RSC Adv. 3 (2013) 2910.

[94] K. Park, Q.F. Zhang, B.B. Garcia, G.Z. Cao, J. Phys. Chem. C, 115 (2011) 4927.

[95] K. Park, Q.F. Zhang, B.B. Garcia, X.Y. Zhou, Y.H. Jeong, G.Z. Cao, Adv. Mater. 22 (2010) 2329.

[96] M.L. Wang, C.G. Huang, Y.G. Cao, Q.J. Yu, Z.H. Deng, Y. Liu, Z. Huang, J.Q. Huang, Q.F. Huang, W. Guo, J.K. Liang, J. Phys. D Appl. Phys. 42 (2009) 155104.

[97] N.O.V. Plank, I. Howard, A. Rao, M.W.B. Wilson, C. Ducati, R.S. Mane, J.S. Bendall, R.R.M. Louca, N.C. Greenham, H. Miura, R.H. Friend, H.J. Snaith, M.E. Welland, J. Phys. Chem. C 113 (2009) 18515.

[98] Q. Peng, J.S. Lewis, P.G. Hoertz, J.T. Glass, G.N. Parsons, J. Vac. Sci. Technol. A 30 (2012) 010803.

[99] C. Fei, J. Tian, Y. Wang, X. Liu, L. Lv, Z. Zhao, G. Cao, Nano Energy 10 (2014) 353.

[100] M. Kato, H. Ono, M. Ichimura, G. Feng, T. Kimoto, Jpn. J. Appl. Phys. 50 (2011) 036603.

[101] M. Zhang, T. Wang, G. Cao, Int. Mater. Rev. 60 (2015) 330. 
[102] L. Zhang, K. Zhao, W. Xu, Y. Dong, R. Xia, F. Liu, L. He, Q. Wei, M. Yan, L. Mai, Phys. Chem. Chem. Phys. 17 (2015) 7619.

[103] W. Xu, K. Zhao, C. Niu, L. Zhang, Z. Cai, C. Han, L. He, T. Shen, M. Yan, L. Qu, L. Mai, Nano Energy 8 (2014) 196.

[104] L.-Q. Mai, F. Yang, Y.-L. Zhao, X. Xu, L. Xu, Y.-Z. Luo, Nat. Commun. 2 (2011) 381.

[105] Y. Zhao, L. Xu, L. Mai, C. Han, Q. An, X. Xu, X. Liu, Q. Zhang, P. Natl. Acad. Sci. USA 109 (2012) 19569. [106] W. Chen, Y. Qiu, S. Yang, Phys. Chem. Chem. Phys. 12 (2010) 9494.

[107] W. Chen, Y.C. Qiu, Y.C. Zhong, K.S. Wong, S.H. Yang, J. Phys. Chem. A 114 (2010) 3127.

[108] N.C. Li, C.R. Martin, B. Scrosati, Electrochem. Solid State Lett. 3 (2000) 316.

[109] D.W. Kim, I.S. Hwang, S.J. Kwon, H.Y. Kang, K.S. Park, Y.J. Choi, K.J. Choi, J.G. Park, Nano Lett. 7 (2007) 3041.

[110] M.S. Park, Y.M. Kang, G.X. Wang, S.X. Dou, H.K. Liu, Adv. Funct. Mater. 18 (2008) 455.

[111] S.J. Han, B.C. Jang, T. Kim, S.M. Oh, T. Hyeon, Adv. Funct. Mater. 15 (2005) 1845.

[112] Q.R. Zhao, Y. Xie, T. Dong, Z.G. Zhang, J. Phys. Chem. C 111 (2007) 11598.

[113] X.W. Lou, Y. Wang, C.L. Yuan, J.Y. Lee, L.A. Archer, Adv. Mater. 18 (2006) 2325.

[114] H.X. Yang, J.F. Qian, Z.X. Chen, X.P. Ai, Y.L. Cao, J. Phys. Chem. C 111 (2007) 14067.

[115] B. Cheng, J.M. Russell, W.S. Shi, L. Zhang, E.T. Samulski, J. Am. Chem. Soc.126 (2004) 5972.

[116] H.B. Wu, J.S. Chen, X.W. Lou, H.H. Hng, J. Phys. Chem. C 115 (2011) 24605.

[117] J.F. Qian, P. Liu, Y. Xiao, Y. Jiang, Y.L. Cao, X.P. Ai, H.X. Yang, Adv. Mater. 21 (2009) 3663.

[118] A. Hossain, G.W. Yang, M. Parameswaran, J.R. Jennings, Q. Wang, J. Phys. Chem. C 114 (2010) 21878.

[119] Y. Wang, J. Tian, C. Fei, L. Lv, X. Liu, Z. Zhao, G. Cao, J. Phys. Chem. C 118 (2014) 25931.

[120] P.V. Kamat, J. Phys. Chem. C 112 (2008) 18737.

[121] Y. Xu, M.A.A. Schoonen, Am. Mineral. 85 (2000) 543.

[122] S.H. Kim, G. Markovich, S. Rezvani, S.H. Choi, K.L. Wang, J.R. Heath, Appl. Phys. Lett. 74 (1999) 317.

[123] C.B. Murray, D.J. Norris, M.G. Bawendi, J. Am. Chem. Soc. 115 (1993) 8706.

[124] Z.X. Pan, H. Zhang, K. Cheng, Y.M. Hou, J.L. Hua, X.H. Zhong, Acs Nano 6 (2012) 3982.

[125] W. Li, X. Zhong, J. Phys. Chem. Lett. 6 (2015) 796.

[126] X. Huang, S. Huang, Q. Zhang, X. Guo, D. Li, Y. Luo, Q. Shen, T. Toyoda, Q. Meng, Chem. Commun. 47 (2011) 2664.

[127] Z. Yang, Q.F. Zhang, J.T. Xi, K. Park, X.L. Xu, Z.Q. Liang, G.Z. Cao, Sci. Adv. Mater. 4 (2012) 1013.

[128] L. Etgar, Materials 6 (2013) 445.

[129] J.-W. Lee, D.-Y. Son, T.K. Ahn, H.-W. Shin, I.Y. Kim, S.-J. Hwang, M.J. Ko, S. Sul, H. Han, N.-G. Park, Sci. Rep. 3 (2013) 1050.

[130] P.K. Santra, P.V. Kamat, J. Am. Chem. Soc. 134 (2012) 2508.

[131] L. Yang, R. Zhou, J. Lan, Q. Zhang, G. Cao, J. Zhu, J. Mater. Chem. A 2 (2014) 3669.

[132] R. Zhou, Q. Zhang, E. Uchaker, J. Lan, M. Yin, G. Cao, J. Mater. Chem. A 2 (2014) 2517.

[133] C. Dong, X. Li, X. Fan, J. Qi, Adv. Energy Mater. 2 (2012) 639.

[134] J. Tian, Q. Zhang, E. Uchaker, Z. Liang, R. Gao, X. Qu, S. Zhang, G. Cao, J. Mater. Chem. A 1 (2013) 6770 .

[135] W.Q. Wu, H.L. Feng, H.S. Rao, Y.F. Xu, D.B. Kuang, C.Y. Su, Nat. Commun. 5 (2014) 3968.

[136] J. Tian, E. Uchaker, Q. Zhang, G. Cao, ACS Appl. Mater. Interfaces 6 (2014) 4466.

[137] J. Tian, L. Lv, X. Wang, C. Fei, X. Liu, Z. Zhao, Y. Wang, G. Cao, J. Phys. Chem. C 118 (2014) 16611.

[138] J.J. Tian, Q.F. Zhang, L.L. Zhang, R. Gao, L.F. Shen, S.G. Zhang, X.H. Qu, G.Z. Cao, Nanoscale 5 (2013) 936. 
[139] J. Tian, Q. Zhang, E. Uchaker, R. Gao, X. Qu, S. Zhang, G. Cao, Energy Environ. Sci. 6 (2013) 3542.

[140] S. Yodyingyong, X.Y. Zhou, Q.F. Zhang, D. Triampo, J.T. Xi, K. Park, B. Limketkai, G.Z. Cao, J. Phys. Chem. C 114 (2010) 21851.

[141] D.B. Mitzi, J. Mater. Chem. 14 (2004) 2355.

[142] W. Shockley, H.J. Queisser, J. Appl. Phys. 32 (1961) 510.

[143] S.D. Stranks, H.J. Snaith, Nat. Nanotechnol. 10 (2015) 391.

[144] N.J. Jeon, J.H. Noh, Y.C. Kim, W.S. Yang, S. Ryu, S.I. Seok, Nat. Mater. 13 (2014) 897.

[145] J.A. Christians, J.S. Manser, P.V. Kamat, J. Phys. Chem. Lett. 6 (2015) 852.

[146] G.E. Eperon, V.M. Burlakov, P. Docampo, A. Goriely, H.J. Snaith, Adv. Funct. Mater., 24 (2014) 151.

[147] N. Li, H. Dong, H. Dong, J. Li, W. Li, G. Niu, X. Guo, Z. Wu, L. Wang, J. Mater. Chem. A 2 (2014) 14973.

[148] Z. Xiao, Q. Dong, C. Bi, Y. Shao, Y. Yuan, J. Huang, Adv. Mater. 26 (2014) 6503.

[149] G. Li, K.L. Ching, J.Y.L. Ho, M. Wong, H.-S. Kwok, Adv. Energy Mater. 5 (2015) 1401775.

[150] B. Li, L. Guo, C. Fei, T. Shen, J. Tian, X. Qu, G. Cao, ACS Appl. Mater. Interfaces (2016) Under Revision.

[151] L. Guo, B. Li, C. Fei, J. Tian, G. Cao, Submitted (2016).

[152] Z. Zhao, X. Chen, G. Cao, Submitted (2016).

[153] M.S. White, D.C. Olson, S.E. Shaheen, N. Kopidakis, D.S. Ginley, Appl. Phys. Lett. 89 (2006) 143517.

[154] F. Zhang, X. Xu, W. Tang, J. Zhang, Z. Zhuo, J. Wang, J. Wang, Z. Xu, Y. Wang, Sol. Energ. Mat. Sol. C 95 (2011) 1785.

[155] S.K. Hau, H.-L. Yip, N.S. Baek, J. Zou, K. O'Malley, A.K.Y. Jen, Appl. Phys. Lett. 92 (2008) 253301.

[156] T. Yang, W. Cai, D. Qin, E. Wang, L. Lan, X. Gong, J. Peng, Y. Cao, J. Phys. Chem. C 114 (2010) 6849.

[157] C.-Y. Li, T.-C. Wen, T.-H. Lee, T.-F. Guo, J.-C.-A. Huang, Y.-C. Lin, Y.-J. Hsu, J. Mater. Chem. 19 (2009) 1643.

[158] J.-H. Huang, H.-Y. Wei, K.-C. Huang, C.-L. Chen, R.-R. Wang, F.-C. Chen, K.-C. Ho, C.-W. Chu, Energy Environ. Sci. 3 (2010) 654.

[159] H.-L. Yip, A.K.Y. Jen, Energy Environ. Sci. 5 (2012) 5994.

[160] Z. Yin, Q. Zheng, S.-C. Chen, D. Cai, ACS Appl. Mater. Interfaces 5 (2013) 9015.

[161] O. Wiranwetchayan, Q. Zhang, X. Zhou, Z. Liang, P. Singjai, G. Cao, Chalcogenide Lett. 9 (2012) 157.

[162] J. Xi, O. Wiranwetchayan, Q. Zhang, Z. Liang, Y. Sun, G. Cao, J. Mater. Sci-Mater. EL. 23 (2012) 1657.

[163] Z. Liang, Q. Zhang, O. Wiranwetchayan, J. Xi, Z. Yang, K. Park, C. Li, G. Cao, Adv. Funct. Mater. 22 (2012) 2194.

[164] J.-L. Lan, Z. Liang, Y.-H. Yang, F.S. Ohuchi, S.A. Jenekhe, G. Cao, Nano Energy 4 (2014) 140.

[165] J.-L. Lan, S.-J. Cherng, Y.-H. Yang, Q. Zhang, S. Subramaniyan, F.S. Ohuchi, S.A. Jenekhe, G. Cao, J. Mater. Chem. A 2 (2014) 9361. 